\title{
Abundance status of flora in Mananga-Kotkot- Lusaran Watersheds, Cebu, Philippines
}

\author{
Justino M. Quimio \\ Department of Forest and Wildlife management, College of Forestry and Natural \\ Resources, Leyte State University, Baybay, Leyte, Philippines
}

\section{ABSTRACT}

Quimio, J. M. 2006. Abundance Status of Flora in Mananga-Kotkot-Lusaran Watersheds, Cebu, Philippines. Ann. Trop. Res. 28(2):53-75.

The paper describes the abundance status of forests and their species composition in the Mananga-Kotkot-Lusaran Watershed of Metro Cebu, Philippines. Data collection and analysis were undertaken according to the Braun-Blanquet (1964) methodology.

Six vegetation types, such as grassland, brushland, pioneer vegetation, young plantation, 60 zyear old tanguile (Shorea polysperma) plantation and old-growth forest forest were sampled in 69 plots. The range of occurrence of species in sampled vegetation types is discussed. The study had recorded 414 species, in 249 genera and 103 families. They included 47 species of large trees, 71 medium trees, 118 small trees, 2 straggler figs, 7 shrubs, 2 palms, 74 erect herbaceous plants, 21 woody lianas, 32 grasses, 22 ferns and 1 moss. Aerial plants were not included in the inventory.

Seven patches of natural growth remained extant in the watersheds but only one, the 40-hectare Tabunan forest patch, was big enough to have interior type forest. The other patches were only about 8 hectares or much less degraded in structure, poor in species, covered by climbing plants and pioneer trees and located either in rocky steep slope or in cliff.

Keywords: flora, diversity, Cebu watershed, Braun-Blanquet

Correspondence: J. M. Quimio Present Address: Department of Forest and Wildlife Management, College of Forestry and Natural Resources, Leyte State University, Baybay, Leyte, Philippines Tel. $(053) 335.4210$.

DOI: 10.32945/atr2824.2006 


\section{INTRODUCTION}

This study was an offshoot of an earlier investigation that was conducted by Quimio et al. (2000), which involved inventory of existing documents regarding Metro Cebu Watersheds and pertinent activities of concerned projects and agencies. In 38 documents reviewed, none presented data on species of forests and no office or agency was doing or planning to do species inventory. Forest resources in the watersheds were described merely based on outdated data in area of major land uses and maps on vegetative cover. Data in most documents were based on one main source, the Department of Environment and Natural Resources. No document has ever attempted to present primary data on watershed resources so that data in older documents were often simply recycled into newer ones. The absence of even a short listing of species in natural vegetation pressured the Philippines-Canada Environmental and Economic Management Project (PCEEM) of the SNCLavalin International, Inc. which was based in Metro Cebu City and involved in the monitoring of Metro Cebu Watersheds, to also finance this follow-up study.

Documentation of floral resources in Metro Cebu Watersheds is urgent in view of the official claim that only 32 hectares of old-growth forests are left existing. Most documents did not even reflect forest as one of the major land uses in the watersheds. This is apparently due to the low significance of the size of forests when compared to area of the more extensive human-induced land cover types. Before the last stands of natural forest are completely lost, it is important to have a record of their species composition. Data on floristic composition of existing forest formations can be used as benchmark if future restoration even of a mere imitation of original forests will become desirable. The benchmark data can help in deciding what species to plant, where to plant which species, and for what species mixture. It is unfortunate for Metro Cebu Watersheds to have no record on timber species that had been cut in the past. Logging was banned in Cebu and Bohol as early as 1860 s (Heaney and Regalado, 1998). Without commercial logging, the loss of forest can be attributed to social pressures on watershed resources.

Big investment has been poured already to vegetative cover development of Metro Cebu Watersheds and more is expected to come. Baseline data on current abundance status of floral resources shall be needed in planning further 
developments, in formulation of effective strategies in protection and as datum points for the monitoring of future developments. Being the first attempt to record floral resources, the species list in this study shall serve as an initial contribution towards a more complete floral inventory.

The primary objective of the study was to describe the abundance status of floral resources in the upper catchment area of Metro Cebu Watersheds. The specific objectives were to categorize existing vegetation types in the study area, describe and differentiate the species composition of each vegetation types, and assess the level of diversity of floral resources.

\section{METHODOLOGY}

\section{The study area}

The island of Cebu is approximately $215 \mathrm{~km}$ long, with a maximal width of $35 \mathrm{~km}$ and total land area of 508, 839 hectares. The topography is predominantly rolling to hilly, with about $30 \%$ of the area having slopes of $18 \%$ and lower. The northern part of the island has type IV climate and receiving more precipitation than the southern part. The southern part that includes Compostela and Cebu City has Type III climate, which is characterized as having no pronounced dry season, relatively dry from November to April and wet during the rest of the year. Average rainfall in Cebu City is $1,560 \mathrm{~mm}$ (DENR, 1990).

Metro Cebu Watersheds include the Mananga Watershed Forest Reserve, Kotkot River Watershed Reserve and Lusaran River Watershed Reserve, or simply the Mananga-Kotkot-Lusaran watersheds. The watersheds of Mananga and Kotkot drain and supply water to the metropolis of Cebu City. Unlike Mananga and Kotkot watersheds, which are complete catchment from headwaters to oceans, Lusaran watershed is a sub-basin of Balamban River that empties into the Tanon Strait towards the other side of Cebu Island. Lusaran is currently not contributing to water supply of Metro Cebu but can later be tapped by rerouting part of its water flow via Kotkot River. KotkotLusaran watersheds have a combined area of 15, 162 hectares while Mananga Watershed has 6,823 hectares or a total of 21,985 hectares. Mananga 
Watershed has a mean annual rainfall of $1,700 \mathrm{~mm}$ (1980-89 data) and the river has an average discharge of $1.4 \mathrm{cu} . \mathrm{m} / \mathrm{s}$. (Electrowatt, 1981). Among the three watersheds, only Lusaran Watershed has some remnant patches of natural forest so that data collection was done in these forest patches and in second growth at upper catchment area of Mananga and Kotkot Watersheds.

Pre-tertiary basement rocks consisting of metamorphosed volcanic and sedimentary rocks such as limestone, sandstone, and shale underlie the three watersheds. In Lusaran and upper catchment of Mananga and Kotkot watersheds, the most dominant parent materials are basalt, shale/mudstone, limestone, diorite and, to a lesser extent, conglomerates. The soil is predominantly clay loam to clay. The sampling area has elevation of $500 \mathrm{~m}$ to $800 \mathrm{~m}$ the highest point the water divide of the three watersheds meet.

About $60 \%$ of the Mananga Watershed and $53 \%$ of the Kotkot-Lusaran watersheds are classified as permanent forest land. With only small patches of forests remaining, this indicates that lands were already largely converted into cropland and other uses. Farmers push high in the mountains even in steep slopes in search for arable lands (Flieger and Cusi, 1998). Population growth in Metro Cebu highlands is reported to be 2.94\% per year in 1990 to 1995. Congestion in the lowland areas and influx of migrants form other provinces or islands also put pressure towards building more homes by urban population in the uplands.

\section{Sampling method}

The field methods used in the data collection was based on BraunBlanquet (1964) methods in plant sociology. It started with reconnaissance survey to have an overview of the general features of the vegetation, identify potential sampling areas, distinguish representative vegetation types to be sampled, identify sampling points for each vegetation types and decide on number of plots to be taken per vegetation type. Vegetation types were recognized based on observation of variation in species composition and physiognomic features. The vegetation types sampled, number of plots per vegetation type and plot sizes used are given in Table 1. Plots in wooded vegetation, such as old-growth forest, tanguile plantation, mangium plantation and pioneer vegetation were had $20 \mathrm{~m} \times 20 \mathrm{~m}$ in size. Four plots each were 
taken in old-growth forest and tanguile plantation. Plots in brushland and grassland were smaller, ranging from 9 to 100 sqm depending on the size of plants and degree of homogeneity in the sample vegetation. Because plots were smaller and data collection faster, higher number of plots was taken in grassland, brushland and pioneer stands. In mangium plantations, only 4 plots were taken because the vegetation of the undergrowth was highly comparable to grassland and brushland and it differed only by having a canopy of mangium trees. Most species in mangium were also observed in grassland and brushland and having more plots will not likely add so much to the number of species in the overall species list of the inventory.

Within each vegetation type, sample points with varied physiognomic character and species mix were taken to capture vegetation with varying species composition, with the purpose of increasing the chance of recording as many species as possible within the planned number of plots to sample. Sampling, therefore, was not random but purposive.

\section{Data collection}

In each plot, the boundary was demarcated and all species were listed. Except for brushland and grassland, separate listings for species in tree layer and for species in the undergrowth were done. Species listed in the tree layer were those reaching the height of at least 7 meters. After completing the list, plot cover dominance by each of the listed species was determined and recorded. Recording of plot cover dominance by species was based on BraunBlanquet scale in Table 2. Other data about the plots were then recorded. These included plot number, size of plot, location, physiographic location on the slope, ground inclination, soil type, soil depth, rockiness, disturbance and management history, vegetation type, overall plot cover and canopy height. Trees with a diameter-at-breast (DBH) of at least $20 \mathrm{~cm}$ were measured for $\mathrm{DBH}$, height to first major branch and total tree height. The species names of trees were also recorded.

\section{Data analysis and interpretation}

Plot data and vegetation were presented on a vegetation table. In the vegetation table, species are listed at the left-hand side and opposite each 
Table 1. Location, vegetation types, number of plots and plot sizes in sampling

\begin{tabular}{|c|c|c|c|c|c|}
\hline Watershed & $\begin{array}{l}\text { Lusaran } \\
\text { \& Kotkot }\end{array}$ & Lusaran & Mananga & Total & $\begin{array}{l}\text { Plot size } \\
\text { (sq. m.) }\end{array}$ \\
\hline Barangay/Sitio & Cantipla & Tabunan & Cantipla & & \\
\hline $\begin{array}{l}\text { Old-growth } \\
\text { forest } \\
\text { Old tanguile }\end{array}$ & - & 4 & - & 4 & 400 \\
\hline $\begin{array}{l}\text { plantation } \\
\text { Mangium }\end{array}$ & 4 & - & - & 4 & 400 \\
\hline $\begin{array}{l}\text { plantation } \\
\text { Pioneer }\end{array}$ & 4 & - & - & 4 & 400 \\
\hline vegetation & 6 & 4 & 4 & 14 & 400 \\
\hline Brushland & 15 & - & - & 15 & $16-50$ \\
\hline Grassland & 28 & - & - & 28 & $9-100$ \\
\hline Total & 57 & 8 & 4 & 69 & 11,500 \\
\hline
\end{tabular}

Table 2. Braun-Blanquet plot cover dominance scale used in recording vegetation data

\begin{tabular}{ll}
\hline Scale Code & Plot Cover Description \\
\hline 5 & $75 \%-100 \%$ plot cover \\
4 & $50 \%-75 \%$ plot cover \\
3 & $25 \%-50 \%$ plot cover \\
B (representing 2B) & $15 \%-25 \%$ plot cover \\
A(representing 2A) & $5 \%-15 \%$ plot cover \\
M(representing 2M) & $<5 \%$ plot cover over 50 individuals \\
1 & $<5 \%$ plot cover; $6-50$ individuals \\
+ & $<5 \%$ plot cover $; 3-5$ individuals \\
$\mathrm{R}$ & $<5 \%$ plot cover $; 1-2$ individuals \\
\hline
\end{tabular}


species are columns of entries on cover dominance. Each column represents one plot so that these columns indicate in which plot each species were recorded. Occurrence of species plots is indicated by a dot. For species composition in a plot, this can be determined by simply looking on all species that have scale code entries along the column that represents the plot. Dots in columns indicate absence of species.

Discussion of floral diversity was limited to number of species, genera and families and dominant to life forms in vegetation types. Similarity in species composition between vegetation types was analyzed through the use of Jaccard indices. Tree components of the old tanguile plantation and Tabunan forest were compared in terms of diversity and frequency of species. The floral inventory did not include aerial plants.

\section{RESULTS AND DISCUSSION}

\section{Patch analysis}

The reconnaissance survey has confirmed that the remaining natural growth in Metro Cebu Watersheds was highly fragmented into only few small patches. With the exception of only one patch, all forest patches had been severely degraded in terms of species richness, vegetative structure, timber species and forest patch connectivity. While the patches are believed to contain high diversity of forest flora and were identified by local agencies to constitute the "biodiversity cluster" of Metro Cebu Watersheds, only one patch was big enough to contain interior type forests.

The biggest and only patch with intact natural growth was located in Barangay Tabunan, thus, also called here as Tabunan forest. Based from the most recent forest cover map available, the Tabunan forest should be at least 40 hectares. It has elongated shape, with 4 wider portions and bulges that are alternated by narrow parts and extended fingers in the periphery. The narrow parts and fingers had exterior type forest while the interior type forests were confined inside the bulges. This made interior forests much reduced in size, forming separate islets within the patch. The size of interior type forests was further reduced by the presence of a large dome of limestone rock that is bare 
of vegetation in its broadest part.

The exterior type forest can be characterized by having sparsely distributed small trees, predominance of pioneer trees, canopy gaps full of climbers and straggling figs and ground with exposed limestone boulders that are interspersed with pockets of acidic soils. In the interior, most trees were anchored on acidic soils that is common in limestone areas. The patches of limestone are shallow and overlying the more dominant acidic parent materials such as basalt, andesite and diorite. These observations should correct the common generalization in most local documents that suggest Cebu forests to be of molave type and limestone as the soil parent material in watersheds. The limestone rocks in remaining forests may explain how they escaped destruction by cultivation.

There were two other forest patches in the area that can be interesting for conservation purposes because of size and presence of timber species. These are the patches in Sitio Cantipla of Barangay Tabunan and in Barangay Magsaysay. The patch in Sitio Cantipla, about 7 hectares in size, was being promoted local conservationists as the show window of forest diversity in Cebu. It has strategic advantage by having thick canopy of trees that is observable direct from the transcentral highway. The reconnaissance survey, however, found that it is not a natural growth forest but an established plantation of tanguile (Shorea polysperma) trees. Local foresters claimed to have no information regarding planting history in the area. However, the obvious dominance, clear linear arrangement and apparent homogeneity in age and size of tanguile trees indicates the primary characteristics of a plantation. The observed difference in floristic and physiognomic structure of this plantation as compared to Tabunan forest provided the primary reason to include it in the sampling.

The forest patch in Barangay Magsaysay had second-growth forest, which was characterized by near absence of large timber, though several valuable timber species including the dipterocarps still existed at moderate frequencies. Most species in this patch were also observed in Tabunan forest so that this patch was excluded from sampling.

All other patches in the study area were only few hectares in size, mostly having exterior type and pioneer vegetation and located in cliffs and rocky ridges. They were covered by mixture of small timber, pioneer trees and 
climbers. Through these patches can certainly have species not found in the sampled patches, they were excluded in sampling or were reserved for more complete listing of species in future inventories.

The dominant vegetative covers that surround forest patches included brushland, grassland, mango plantation, tree plantation and cropland. The settled areas ranged from a regular barangay-size to small groupings of houses or single household in isolated farmlots. The presence of settlers and human activity in most part of slopes can explain predominance of open areas and suppression of vegetative succession. The distance of one to few kílometers between patches have markedly reduced connectivity in view of seed dispersal, pollen exchange, wildlife migration and other flow processes.

\section{Timber in forests}

The averages of tree height in Tabunan forest and tanguile plantation were $42.25 \mathrm{~m}$ and $33.25 \mathrm{~m}$, respectively. In the Tabunan forest, 22 species of trees having a DBH of at least $20 \mathrm{~cm}$ were recorded (Table 3). These included 3 species of dipterocarp namely: Shorea polysperma, Shorea contorta and Parashorea plicata. More dipterocarp species were also observed occurring outside the 4 sample plots. The absence of molave (Vitex parviflora),or its apparently low frequency if at all present, in Tabunan Forest suggests that such patch is not a molave type forest, but a dipterocarp type forest.

In the tanguile plantation, only 6 species of trees having DBH of at least $20 \mathrm{~cm}$ were recorded. Tanguile got relative frequency of $70 \%$, being the main species in the plantation. Trees of other species were much smaller and younger than tanguile trees. The low number of timber species and frequency of those species represented, except for tanguile, indicated the very slow pace of tree regeneration inside the plantation. The nearest potential seed source, the Tabunan forest, was about $3 \mathrm{~km}$ away.

\section{Dominant life forms}

Herbaceous plants were the most important components in grassland, brushland, mangium plantation and pioneer vegetation (Table 5). The mangium 
Table 3. Relative frequency of species of trees having DBH of at least $20 \mathrm{~cm}$ intanguile plantaton and Tabunan forest

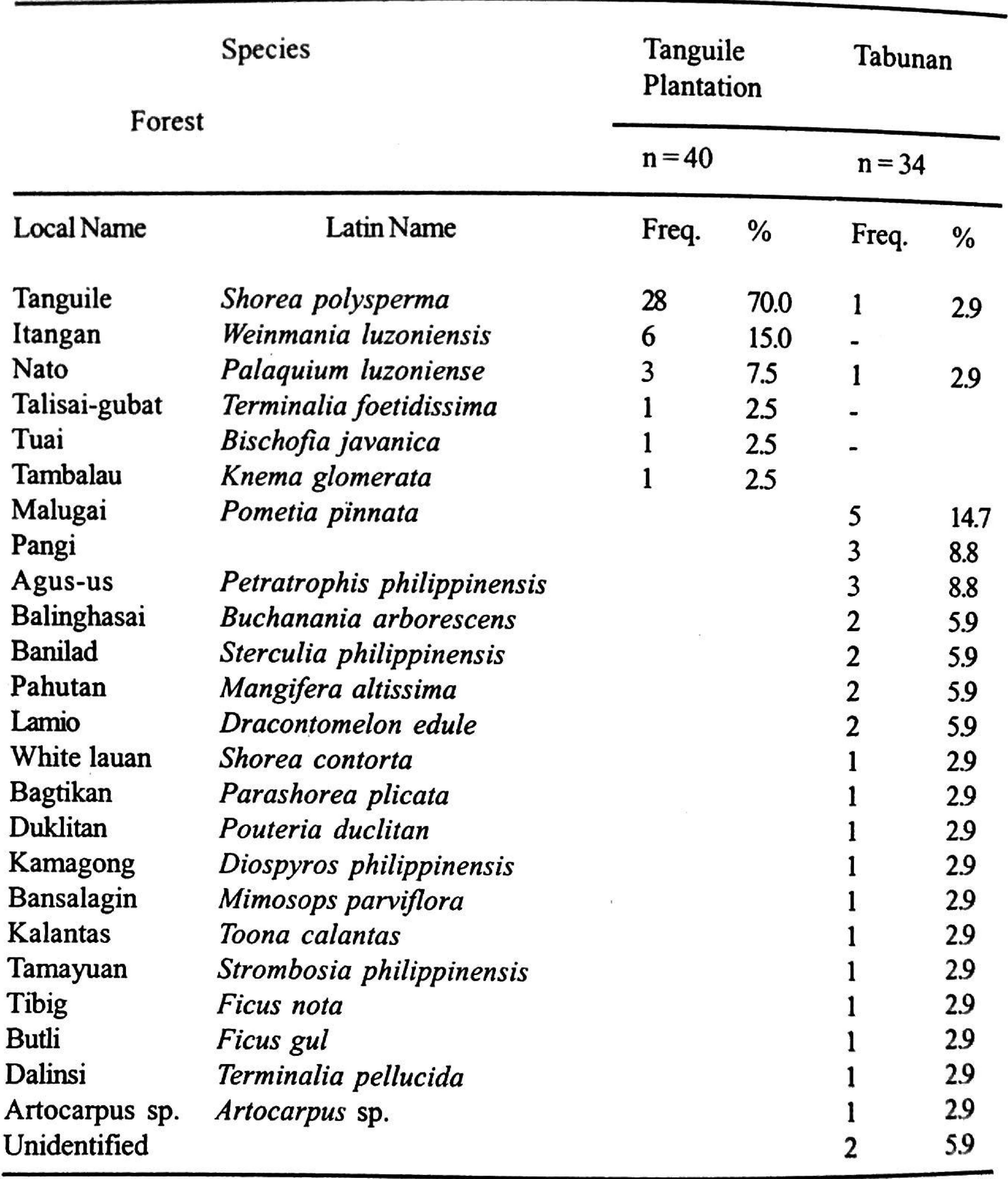

plantation had undergrowth that was dominated by species associated to openland and tree layer of mangium monocrop. Depending on the level of succession in the undergrowth, the dominant life forms in mangium plantation was closely similar to those of grassland, brushland or pioneer vegetation, in addition to mangium. In pioneer vegetation, full-grown pioneer trees were highly observable and the sun-demanding herbaceous species was much reduced. In tanguile plantation and Tabunan forest herbaceous species had been much reduced 
Table 4. Number and relative frequency of species in vegetation types, by plant form, Metro Cebu Watersheds, May 2001.

\begin{tabular}{|c|c|c|c|c|c|c|c|c|c|c|c|c|}
\hline \multirow{2}{*}{$\begin{array}{l}\text { Kind of } \\
\text { Plant } \\
\text { a. Ground Layer }\end{array}$} & \multicolumn{2}{|c|}{$\begin{array}{l}\text { Grass- } \\
\text { land }\end{array}$} & \multicolumn{2}{|c|}{$\begin{array}{l}\text { Brush- } \\
\text { land }\end{array}$} & \multicolumn{2}{|c|}{$\begin{array}{l}\text { Mangium } \\
\text { Plantation }\end{array}$} & \multicolumn{2}{|c|}{$\begin{array}{l}\text { Pioneer } \\
\text { Vegetation }\end{array}$} & \multicolumn{2}{|c|}{$\begin{array}{l}\text { Tanguile } \\
\text { Plantation }\end{array}$} & \multicolumn{2}{|c|}{$\begin{array}{l}\text { Tabunan } \\
\text { Forest }\end{array}$} \\
\hline & No. & $\%$ & No. & $\%$ & No. & $\%$ & No. & $\%$ & No. & $\%$ & No. & $\%$ \\
\hline Grass & 27 & 25 & 17 & 18 & 10 & 15 & 15 & 9 & 5 & 3 & 1 & 1 \\
\hline Herb & 32 & 30 & 26 & 27 & 22 & 33 & 32 & 18 & 21 & 13 & 16 & 13 \\
\hline Shrub & 8 & 7 & 7 & 7 & 7 & 10 & 12 & 7 & 9 & 6 & 4 & 3 \\
\hline Fern & 12 & 11 & 9 & 9 & 7 & 10 & 16 & 9 & 14 & 9 & 2 & 2 \\
\hline Liana & 1 & 1 & 2 & 2 & 0 & 0 & 7 & 4 & 8 & 5 & 7 & 6 \\
\hline Small tree & 14. & 13 & 16 & 17 & 11 & 16 & 58 & 33 & 48 & 29 & 39 & 32 \\
\hline Medium tree & 8 & 7 & 10 & 10 & 6 & 9 & 29 & 17 & 45 & 28 & 33 & 27 \\
\hline Large tree & 0 & 0 & 3 & 3 & $4^{* *}$ & 6 & 25 & 14 & 13 & 8 & 20 & 16 \\
\hline Subtotal & 10 & & 96 & & 6 & 7 & 172 & & 163 & & 122 & \\
\hline \multicolumn{13}{|l|}{ B. Tree layer } \\
\hline Liana & - & & - & & - & - & - & - & 8 & 14 & 8 & 22 \\
\hline Small tree & - & & - & & 1 & 14 & - & - & 18 & 31 & 14 & 39 \\
\hline Medium tree & - & & - & & 2 & 29 & - & - & 12 & 21 & 6 & 17 \\
\hline Large tree & - & & - & & $2 * *$ & 29 & - & - & 16 & 28 & 13 & 36 \\
\hline Others* & - & & - & & 2 & 29 & - & - & 4 & 7 & 7 & 19 \\
\hline Subtotal & - & & - & & 7 & & - & & 58 & & 36 & \\
\hline Total & 10 & & 96 & & 7. & & 17 & & 19 & & 13 & \\
\hline
\end{tabular}

** planted seedlings

but trees and lianas have recorded higher number of specie and frequency. Herbaceous plants in tanguile plantation and Tabunan forest were represented by shade-tolerant species and, therefore, composed of a different set of species as compared to the more sun-demanding species of grassland and brushland.

\section{Similarity in floristic composition}

High degree of similarity in species composition of grassland with brushland, mangium plantation and pioneer vegetation was indicated by the Jaccard similarity index of $0.36,0.43$ and 0.40 , respectively. These suggest that grassland was sharing at least one-third of the species found in the latter three vegetation types. This was consistent with the discussion on commonality in constituent dominant life forms of these vegetation types in Table 4 . The 
Table 5. Jaccard similarity index, Js. (above diagonal),number of common species to vegetation types (below diagonal) andnumber of species, by vegetation types

\begin{tabular}{lccccccc}
\hline $\begin{array}{l}\text { Vegetation } \\
\text { Type }\end{array}$ & $\begin{array}{c}\text { Grass- } \\
\text { land }\end{array}$ & $\begin{array}{c}\text { Brush- Mangium } \\
\text { land }\end{array}$ & $\begin{array}{c}\text { Pioneer } \\
\text { Plantation }\end{array}$ & $\begin{array}{c}\text { Tanguile } \\
\text { Plantation }\end{array}$ & $\begin{array}{c}\text { Tabunan } \\
\text { Forest }\end{array}$ & Total \\
\hline Grassland & & 0.38 & 0.43 & 0.40 & 0.12 & 0.07 & 107 \\
Brushland & 56 & & 0.42 & 0.24 & 0.13 & 0.05 & 96 \\
Mangium Pltn. & 54 & 50 & & 0.26 & 0.08 & 0.07 & 74 \\
Pioneer Type & 91 & 59 & 51 & & 0.28 & 0.28 & 174 \\
Tanguile Pltn. & 30 & 33 & 34 & 81 & & 0.30 & 197 \\
Tabunan Forest & 16 & 11 & 13 & 67 & 71 & & 136 \\
Total & 107 & 96 & 74 & 174 & 197 & 136 & 414 \\
\hline
\end{tabular}

Table 6. Summary of description of plot data

\begin{tabular}{llcccccc}
\hline $\begin{array}{l}\text { Vegetation } \\
\text { Type }\end{array}$ & & $\begin{array}{c}\text { Grass- } \\
\text { land }\end{array}$ & $\begin{array}{c}\text { Brush- Mangium } \\
\text { land }\end{array}$ & Plantation & Pioneer & $\begin{array}{c}\text { Tanguile } \\
\text { Plantation }\end{array}$ & $\begin{array}{c}\text { Tabunan } \\
\text { Forest }\end{array}$ \\
\hline No. of plots & & 32 & 11 & 4 & 14 & 4 & 4 \\
Plot size, sq. m & & $9-100$ & $16-32$ & 400 & 400 & 400 & 400 \\
Slope, in & Ave. & 41.5 & 42.3 & 31.3 & 40.8 & 40.0 & 17.0 \\
degrees & Range & $5-78$ & $30-60$ & $20-35$ & $10-70$ & $25-45$ & $3-35$ \\
Canopy ht, m & Ave. & $0.05-6.2$ & $1.5-6.0$ & $17-18$ & $7-20$ & $26-45$ & $35-45$ \\
& Range & 1.93 & 4.15 & 17.8 & 11.0 & 33.3 & 42.3 \\
PLot cover, \% & Ave. & 85.2 & 88.1 & 70.0 & 76.1 & 66.3 & 66.3 \\
& Range & $25-100$ & $60-100$ & 45.80 & $60-100$ & $60-75$ & $50-75$ \\
No. of species/ & Ave. & $17-41$ & $18-39$ & 35.58 & 2470 & $71-98$ & $63-71$ \\
plot & Range & 22.9 & 26.5 & 44.0 & 47.8 & 86.6 & 62.3 \\
& & & & & & & \\
\hline
\end{tabular}


similarity indices, when comparing the species composition and Tabunan forest, were remarkably low. This reflects the fact that the four earlier mentioned vegetation types are associated to open land while the latter two are forests. The highest number of species in the tanguile plantation and the Tabunan forest were forest species while in the other four vegetation type, herbaceous species associated to open land were more numerous. The Jaccard indices of grassland, brushland, mangium plantation and pioneer vegetation when compared to species composition of the tanguile plantation were $0.12,0.13,0.08$ and 0.28 , respectively. For the Tabunan forest, these were $0.07,0.05,0.07$ and 0.28 , respectively. The relatively higher similarity index between pioneer vegetation and tanguile plantation $(0.28)$ was due to recruitment of shade dependent herbaceous plants and seedlings of woody species in the course of succession.

The Jaccard similarity index for the tanguile plantation and Tabunan forest was 0.30 , indicating that $30 \%$ of the combined list of species were encountered in both of them. Most species that were common to both tanguile plantation and Tabunan forest were pioneer tree species, lianas, climbers, herbs and ferns. In terms of diversity in timber species, the tanguile plantation still retained the character of a monoculture even after its estimated age of about 60 years. Most of timber species in the Tabunan forest were still lacking in the tanguile plantation, an indication of problems in dispersal. The more rapid regeneration by pioneer trees and other undergrowth species in tanguile plantation can be explained by their more efficient dispersal mechanisms, shorter period to maturity and production of small but very numerous seeds.

\section{Site preferences and diversity of species}

Table 6 presents a summary table on plot data on vegetation height, plot canopy cover, ground inclination and number of species per plot. The individual plot data are also shown in Appendix Table 1. The data indicated the relatively steep slopes in the area that were farmed and later occupied by grassland, brushland, mangium plantation and pioneer vegetation. Tabunan forest has gentler slopes but are more rocky compared to plots in other vegetation types. The number of species per plot increased with age of vegetation, suggesting the importance of withdrawal of human disturbance to allow lands to regenerate. The number of species per plot in tanguile plantation was higher compared to 
those in the Tabunan forest, but again, this was due to higher number of nontree species in the undergrowth of tanguile plantation and not due to increased species diversity in trees.

In the vegetation table (Appendix Table 1), the species that were recorded in each plot, the groupings whose occurrence has been confined to only one vegetation type or to a range of vegetation types, the relative frequency in plot groups, and, the plot canopy dominance by species can be determined simply by visual inspection. In the first plot group (Plot 1-12), grassland was dominated by the group of Axonopus compressus but the group of Imperata cylindrica was in most plots absent. Consequently, where the species group of Imperata was present (Plot 13-32), the group of Axonopus compressus was absent most of the time. These suggest differences in site preference among species. While both plot groups (Plot 1-12 and 13-32) were associated to heavy grazing pressure, the group of Axonopus compressus preferred wet areas while the group of Imperata was more frequent in well-drained sites. The species groups represented by Mimosa pudica and Mikania cordata were associated to open land conditions and did not show sensitivity to soil moisture conditions by being present in plots associated to the groups of Axonopus compressus and Imperata cylindrica. Being sun-demanding species, the species groups of Axonopus compressus, Mimosa pudica, Mikania cordata, Imperata cylindica, Rubus risaefolius and Mallotus recinoides were commonly absent in tanguile plantation and Tabunan forest. The species in the group represented by Mallotus recinoides were associated to brushland and pioneer vegetation but very seldom present in open grassland. The group of Mallotus recinoides included the species that were associated with areas in which grazing has been withdrawn for sometime or where initial phase of succession occurs. The group of Scleria scrobiculata occurred in grassland but extended their presence even to the already wooded pioneer vegetation and tanguile plantation, while the group of Dinochloa acutifolia appeared only in pioneer vegetation, tanguile plantation and Tabunan forest (Plot 4869).

In later part of Appendix Table 1, many species are shown to be confined to tanguile plantation (Plot 62-65) and Tabunan forest (Plot 66-69). The species that were recorded in only one or two plots and were listed as footnote of the 
table were mostly forest species encountered in tanguile plantation and Tabunan forest. The high number of species that were encountered in only one or two plots in tanguile plantation and Tabunan forest was an indication that more species can be added to the inventory if sampling would continue.

The combined area of the 69 plots in this inventory was 1.15 ha. A total of 414 species in 249 genera and 102 families were recorded, with 11 liana species unidentified. These included 47 species of large trees, 71 medium trees, 118 small trees, 2 straggler figs, 7 shrubs, 2 palms, 74 erect herbaceous plants, 12 vines, 21 woody lianas, 22 ferns, 1 moss and 32 grasses. The species list for Metro Cebu Watersheds that shows the scientific name, genus, family, local name and life form of species has been prepared but was excluded in this report due to space limitation.

\section{CONCLUSIONS}

Based on the results, the following conclusions could be drawn:

1. The original forests that formerly occupied the watershed was a dipterocarp type forest. It is incorrect to generalize Cebu forests as molave type forest. Molave type forest may occur in the coastal limestone part of Cebu but was not observed in the upper part of Metro Cebu watersheds.

2. The forested area near the transcentral highway that is being promoted to showcase the forest diversity in Cebu, or called as Cebu's "biodiversity cluster" is actually a tanguile plantation.

3. Tabunan forest and the forest in Barangay Magsaysay are the last stands where natural samples of plant generic resources in Metro Cebu Watersheds are preserved. Loss of these two patches shall deprive Metro Cebu from any claim of having a natural forest.

4. Tabunan forest still contains high diversity of flora and requiring more effective protection.

5. Different groupings of species are associated to different vegetation types, or to vegetation with different stages in succession. Forest species need the environment conditions inherent to a forest such that the best way of conserving them is through conservation of natural resources.

6. Regeneration using timber species implantation very slow due to severe fragmentation and poor connectivity between forest patches. 
7. If Tabunan forest will be lost, Metro Cebu would be a biological desert.

\section{RECOMMENDATIONS}

1. More inventory studies on the flora of Metro Cebu watersheds, particularly in the Tabunan forest need to be undertaken;

2. Local governments should give commensurate attention to the seriousness of the need to protect Tabunan forest; and

3. Reforestation efforts should consider enrichment planting with species that are indigenous to the area and establishment of a corridor system to improve connectivity of patches.

\section{ACKNOWLEDGMENT}

The financial support by the PCEEM Project of SNC-LAVALIN International, Inc. to the conduct of the study is highly appreciated.

\section{LITERATURE CITED}

BRAUN-BLANQUET, J. 1964. Pflanzensoziologie. Verlag Hamburg. 861 pp.

ELECTROWATT ENGINEERING SERVICES, LTD. 1991. Cebu Water Supply Project. Feasibility study for a dam on the Mananga River. Volume II. Technical Assistance T. A. 1268. Asian Development Bank and Metropolitan Cebu Water District. Draft Final Report.

FLIEGER, W. and D. R. CUSI. 1998. The Mountains of Cebu and their Inhabitants: Measurements and Estimates. Program on Population-USAID, Honolulu and Office of Population Studies of University of San Carlos. $101 \mathrm{pp}$.

HEANEY, L. R. and J. C. REGALADO, Jr. 1998. Vanishing Treasures. In: Vanishing Treasures of the Philippine Rain Forest. (Heaney, L. R. and J. C. Regalado, Jr. eds. ) The Field Museum, Chicago. 23-60 pp.

QUIMIO, J. M., V. B. ASIO and B. B. DARGANTES. 2000. Analysis of existing data on biodiversity and critical habitat in three protected areas of Cebu. A Project Report. PCEEM. Cebu City. 57 pp. 


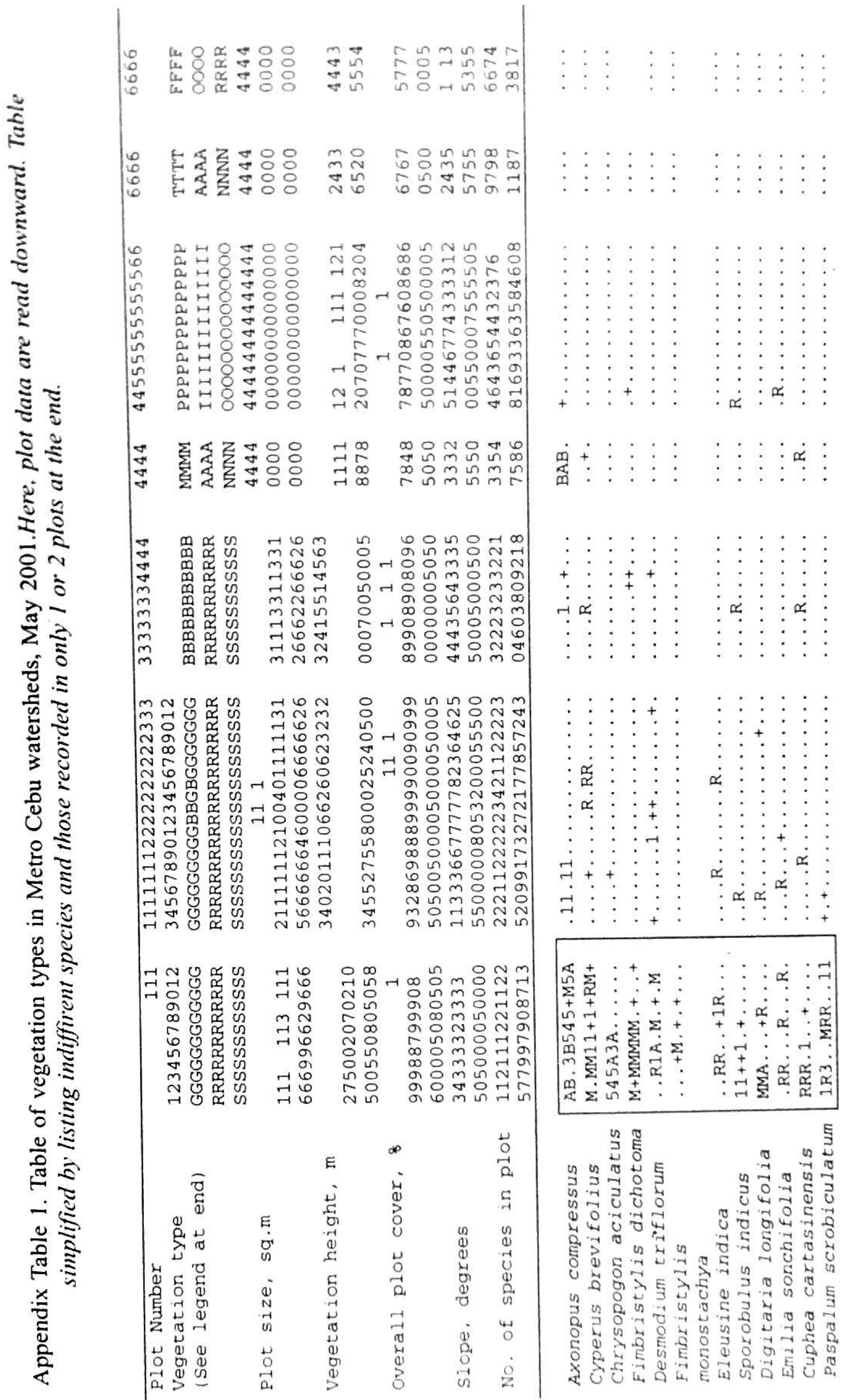




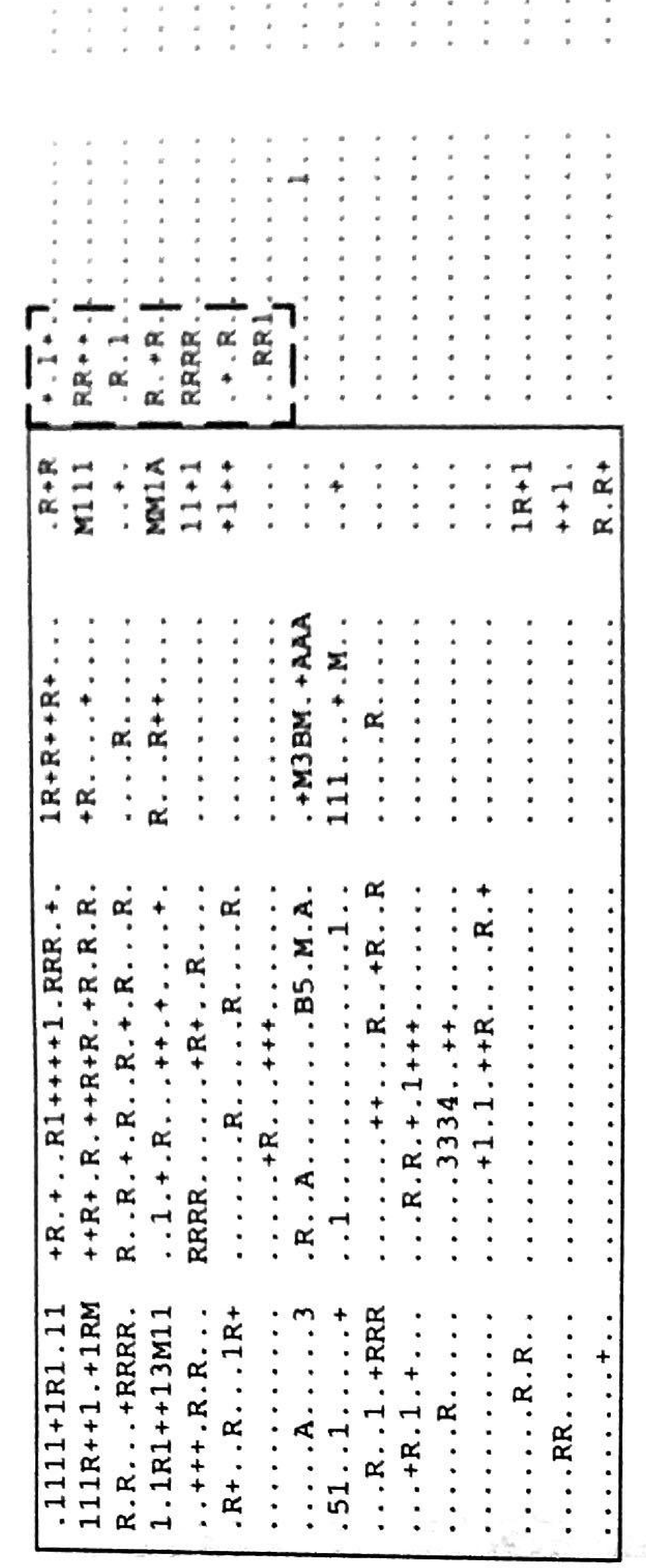

$\dot{t}: \dot{x} \dot{x}::_{+}^{\infty}+\frac{1}{+}$

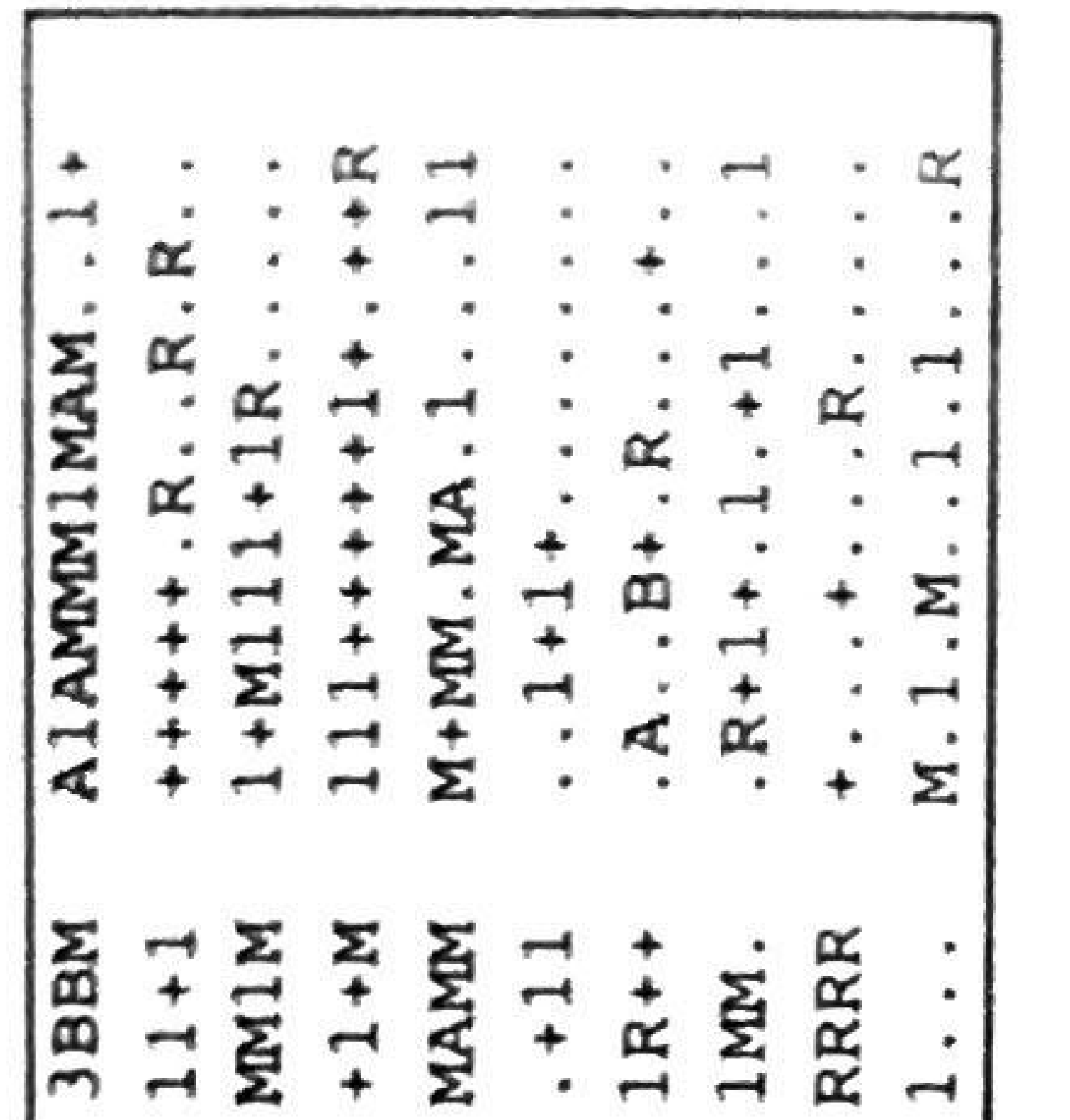

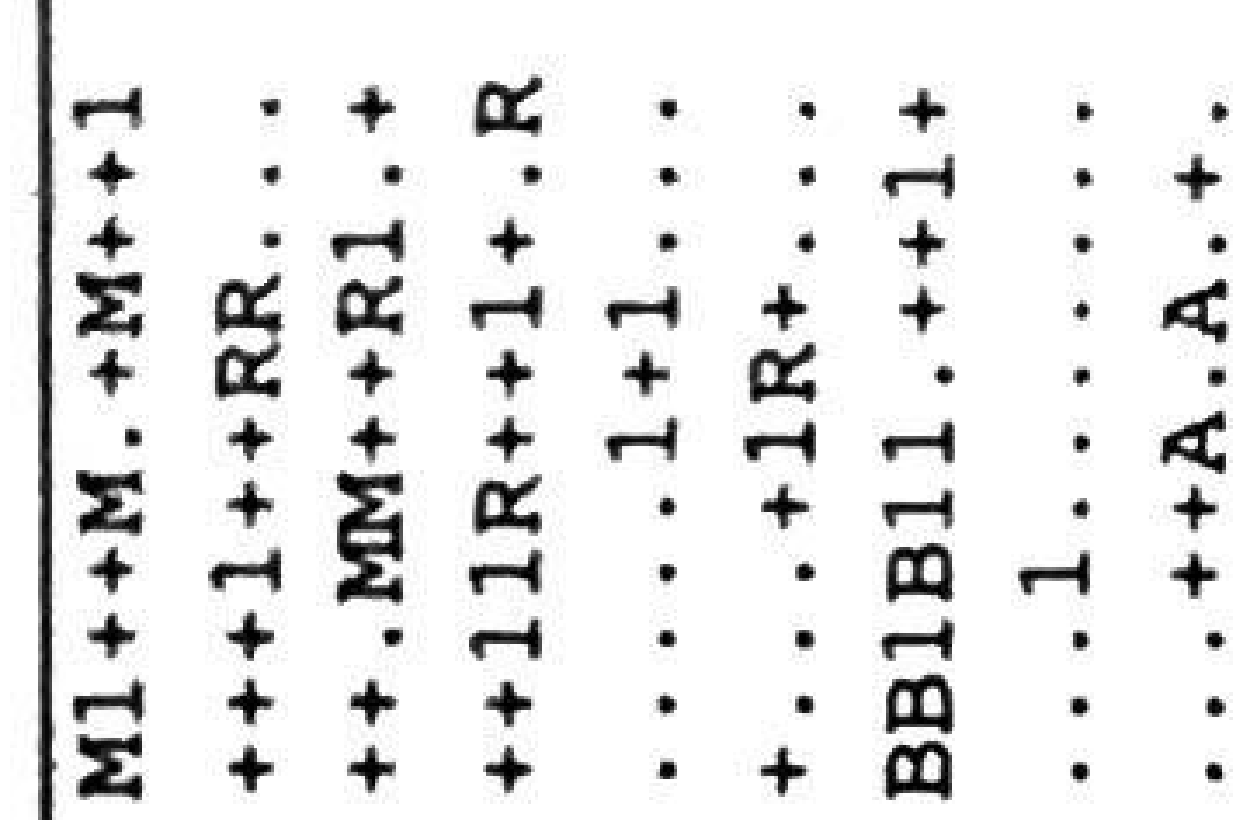

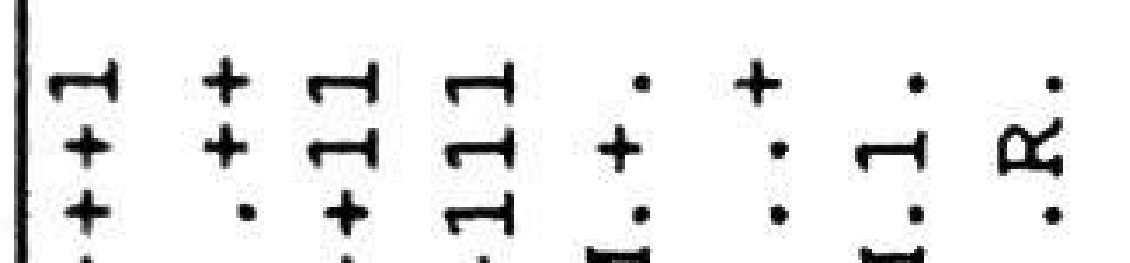

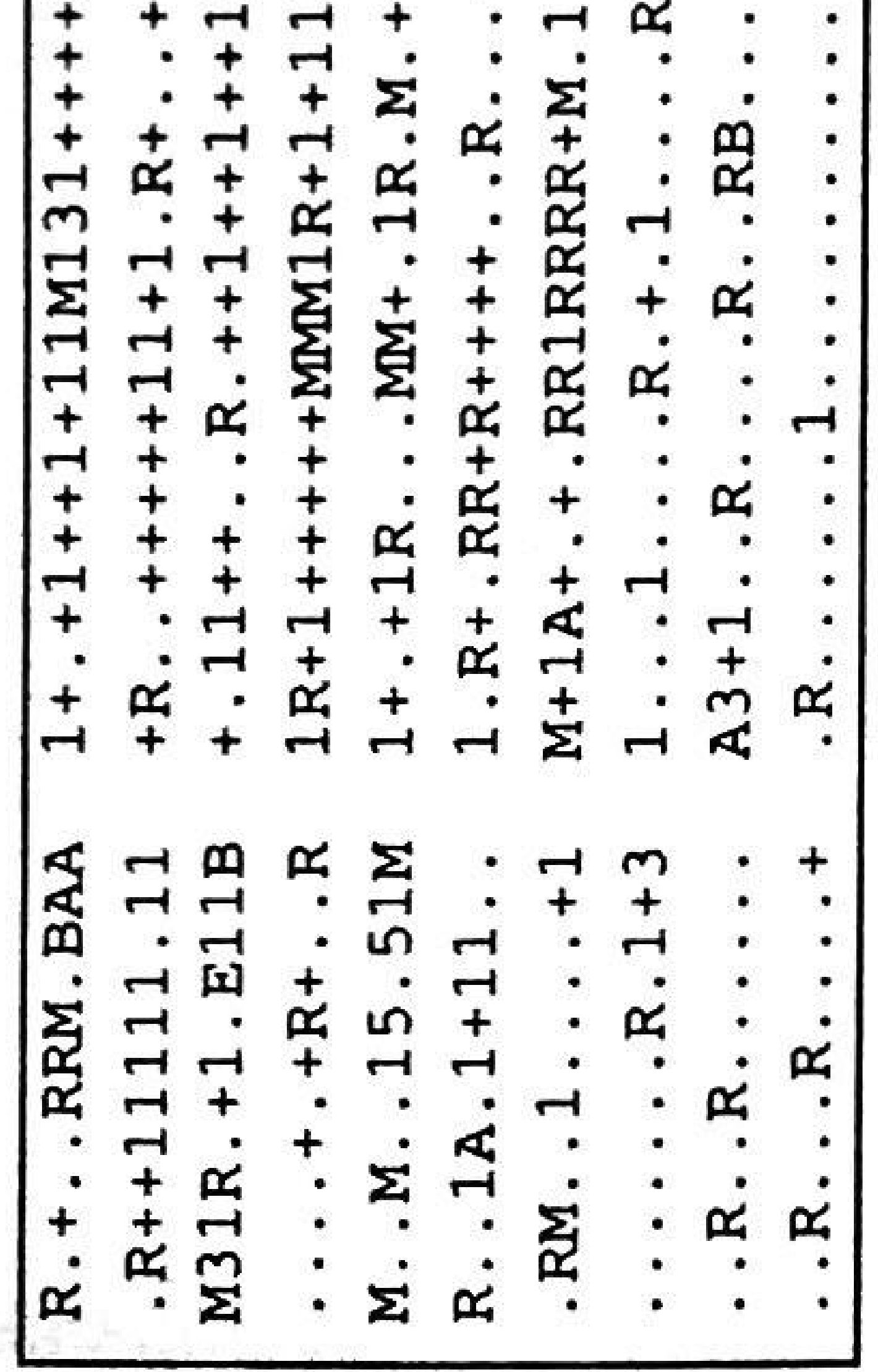

ชุ

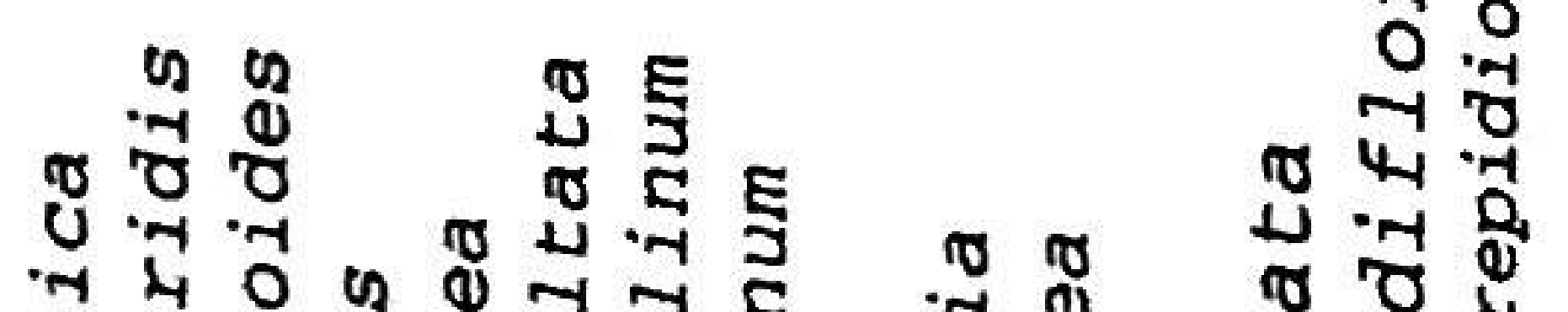

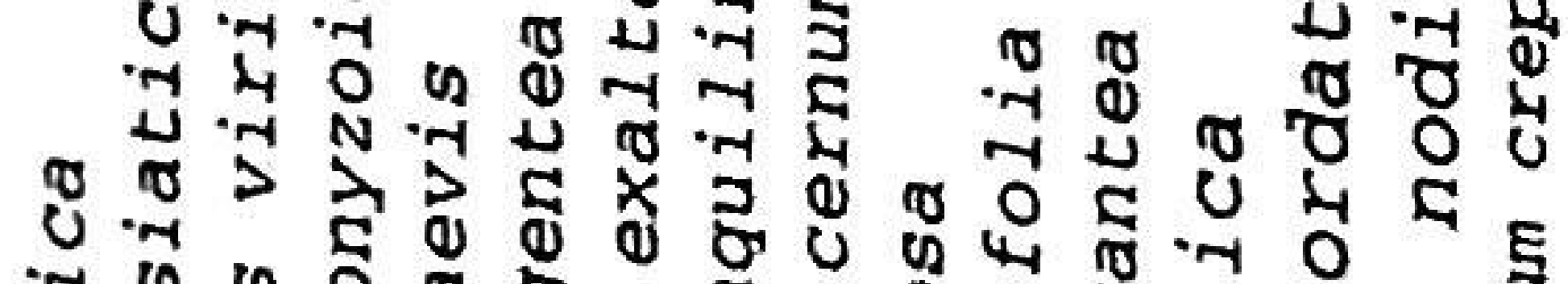
ชิ ว

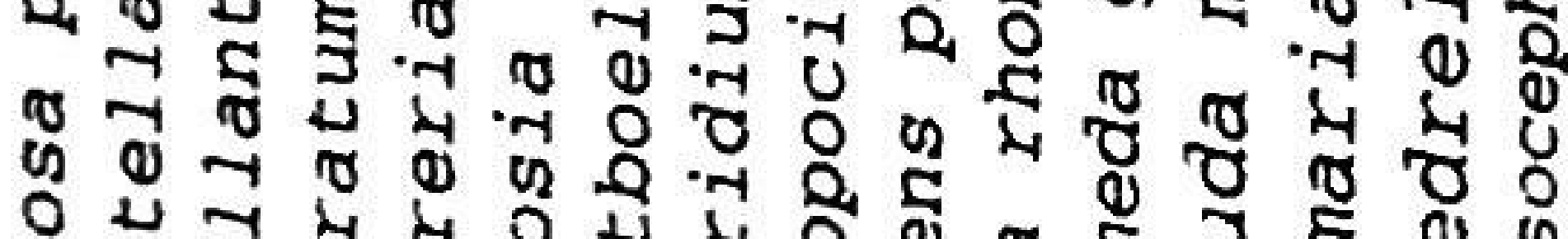

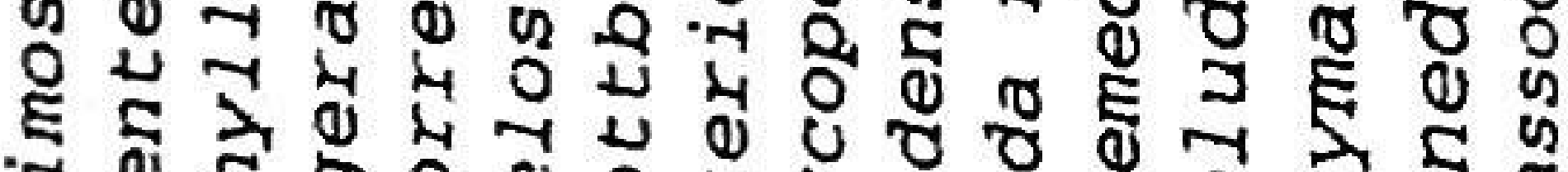

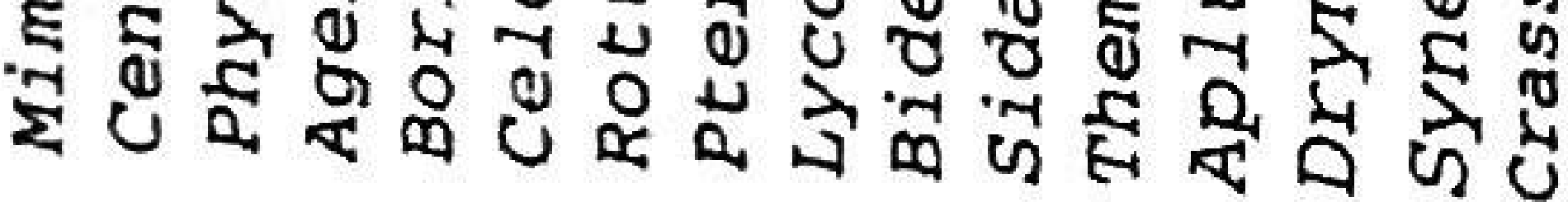

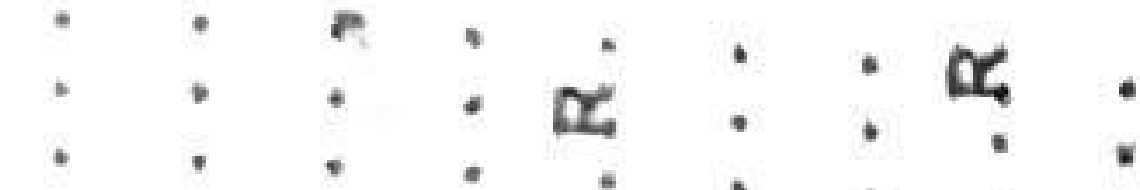




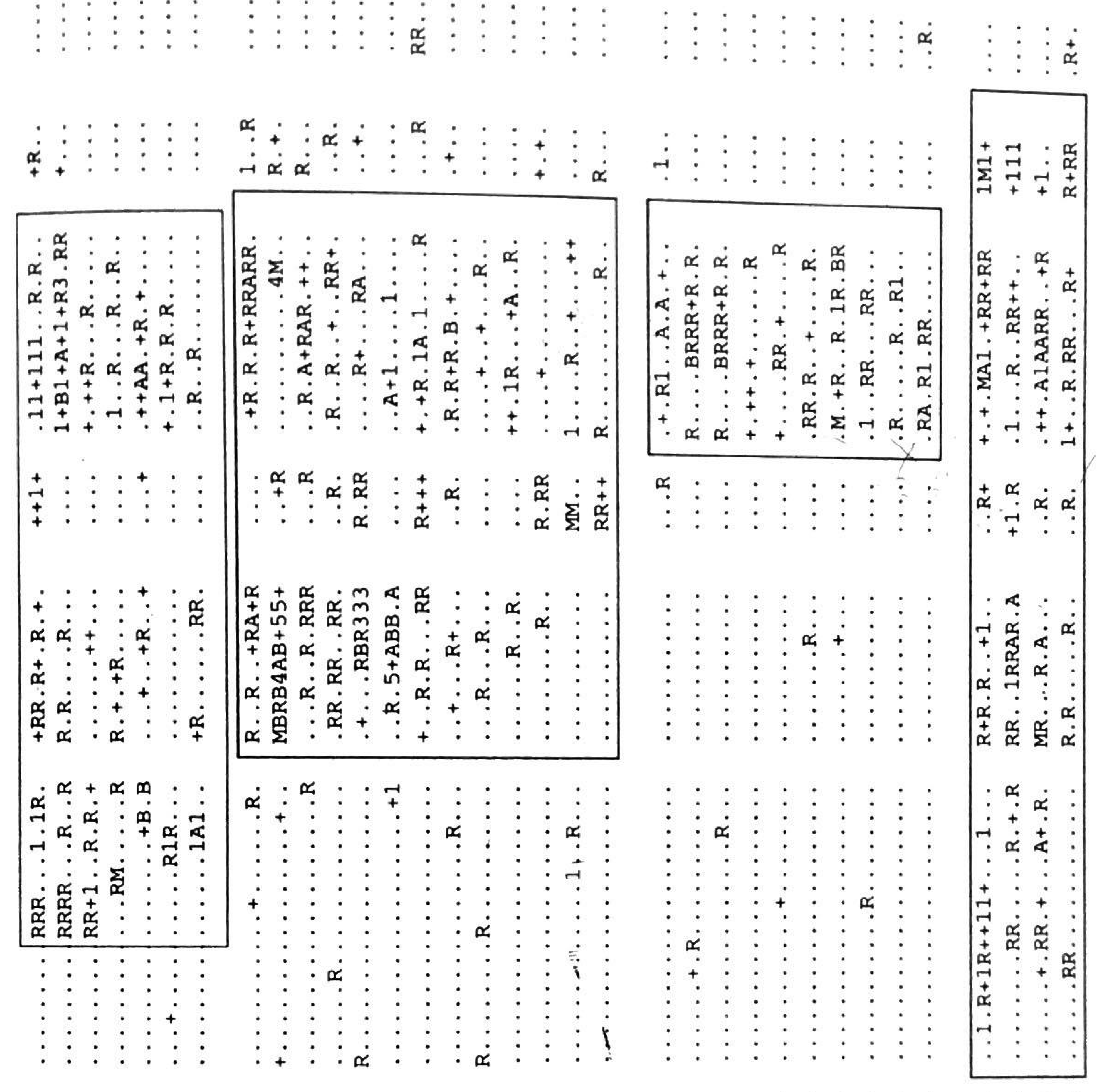

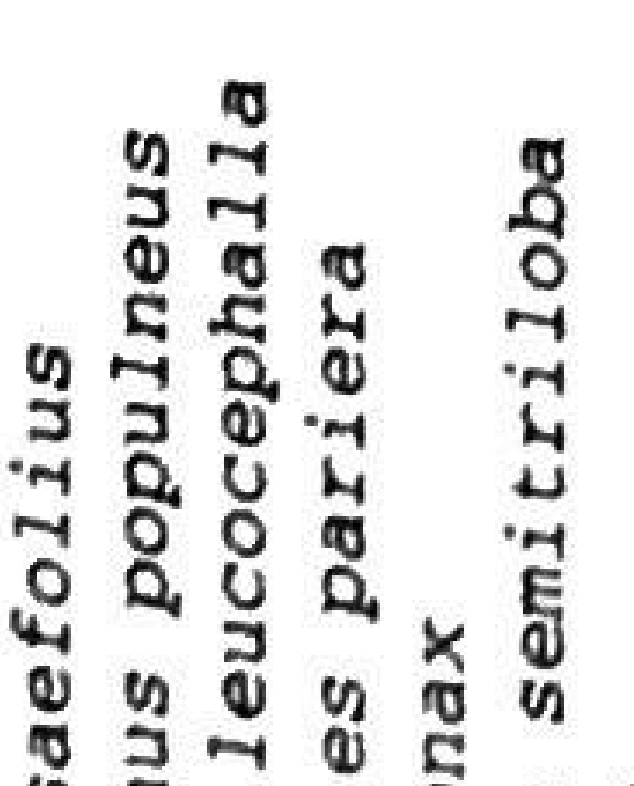

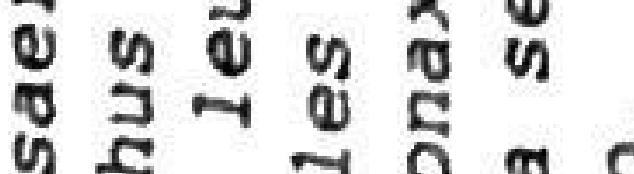
以ू.

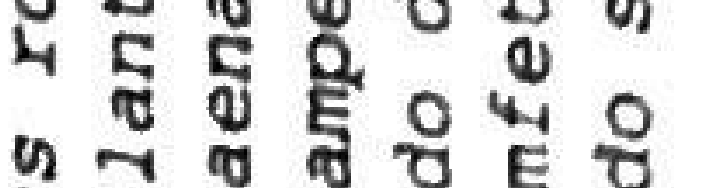
ดี ชี ชิ

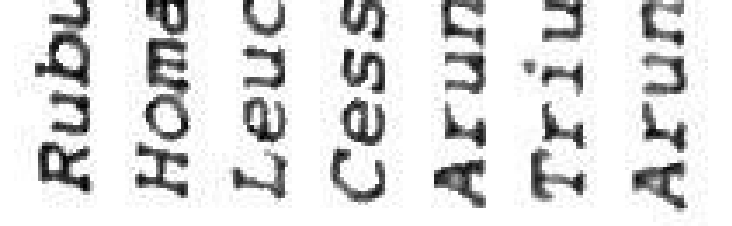

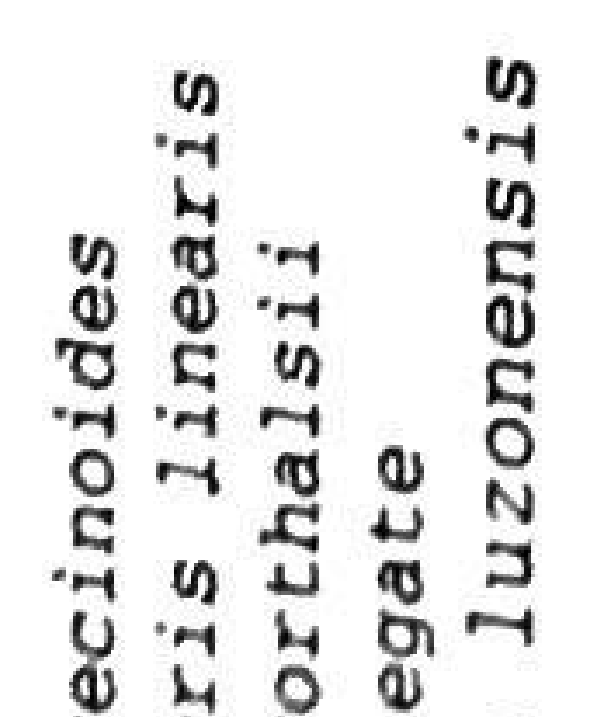

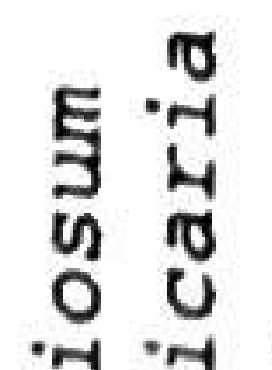
บับ

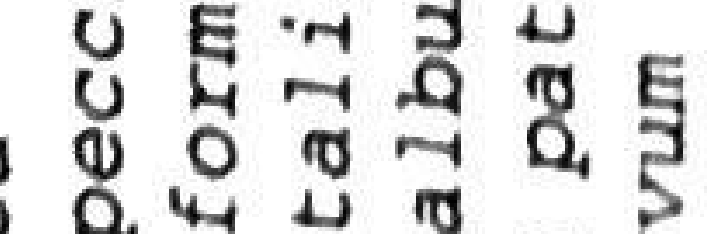
बै 4 ब

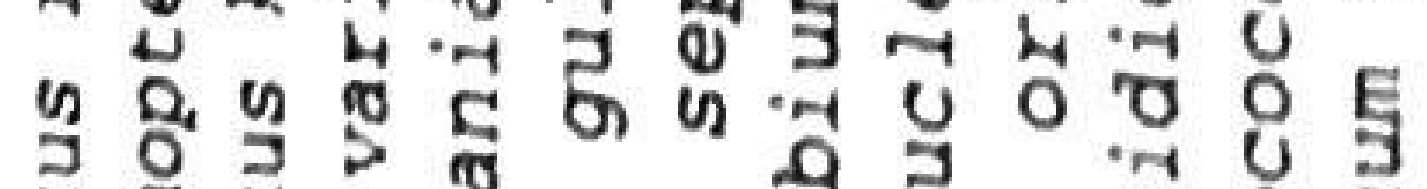
范节的

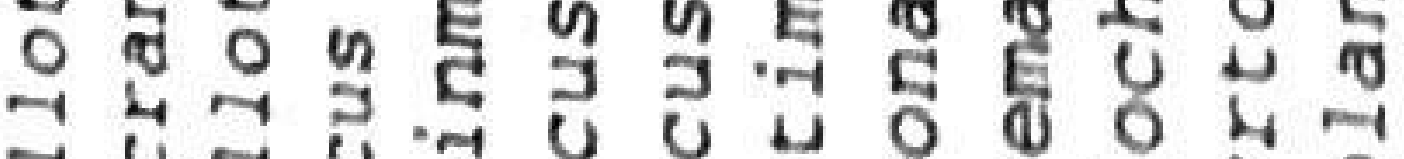
刃ै
ช

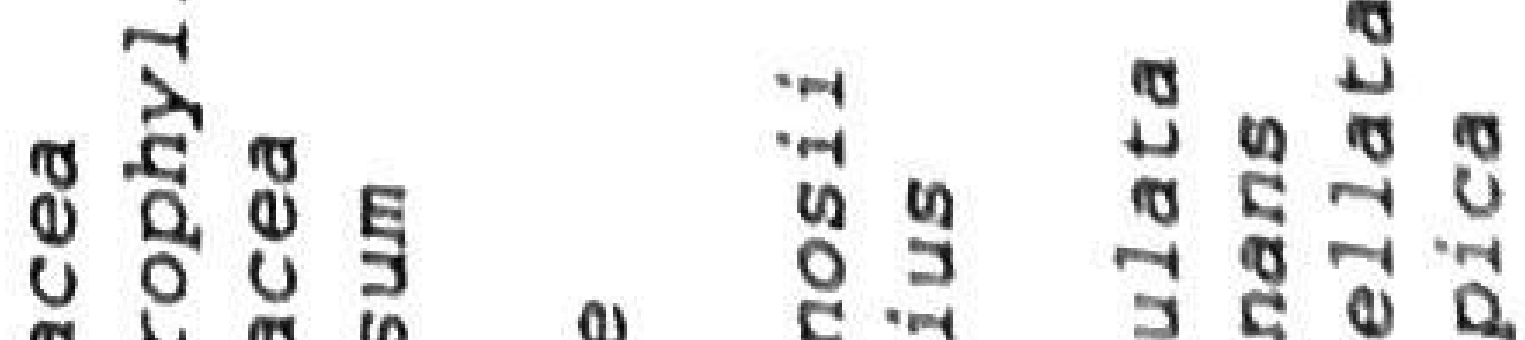

कम ๑ Э吉员

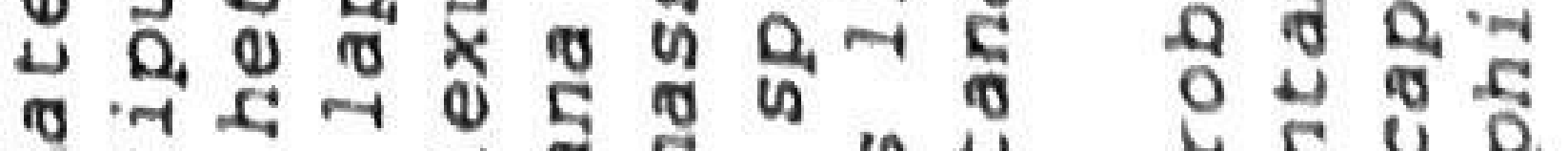

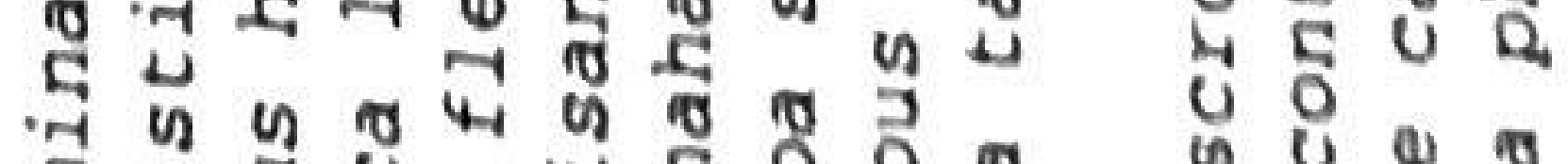
式

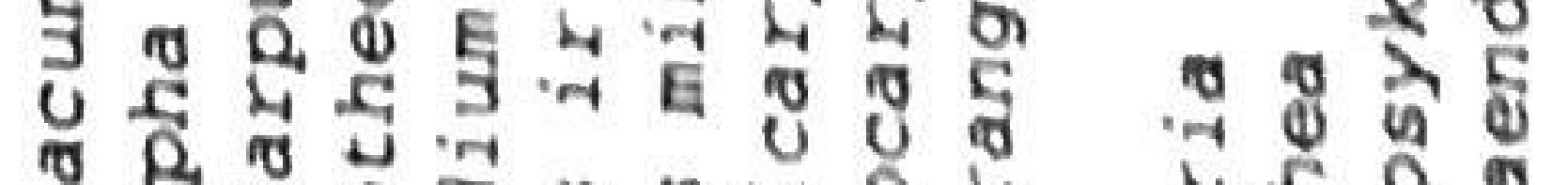
\% 20 \% ซ

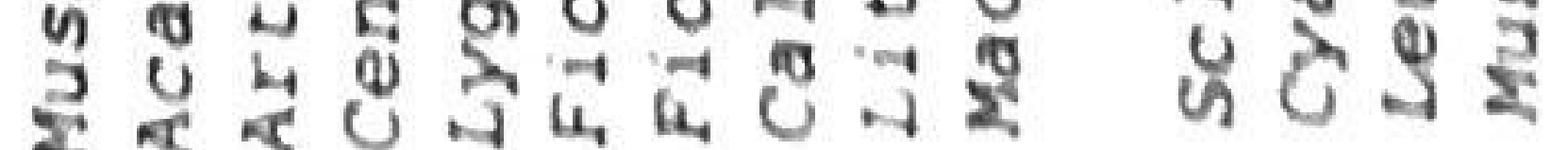



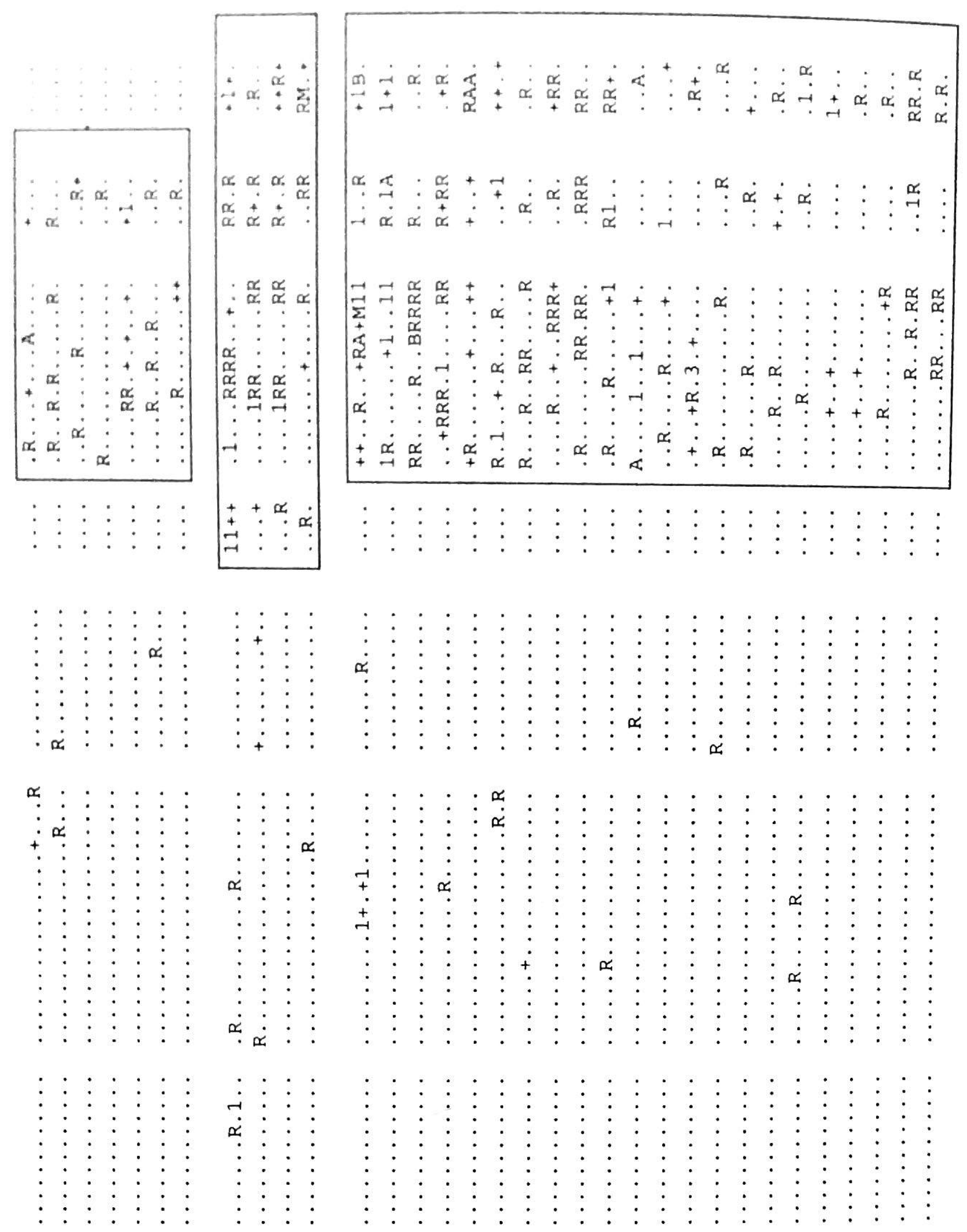


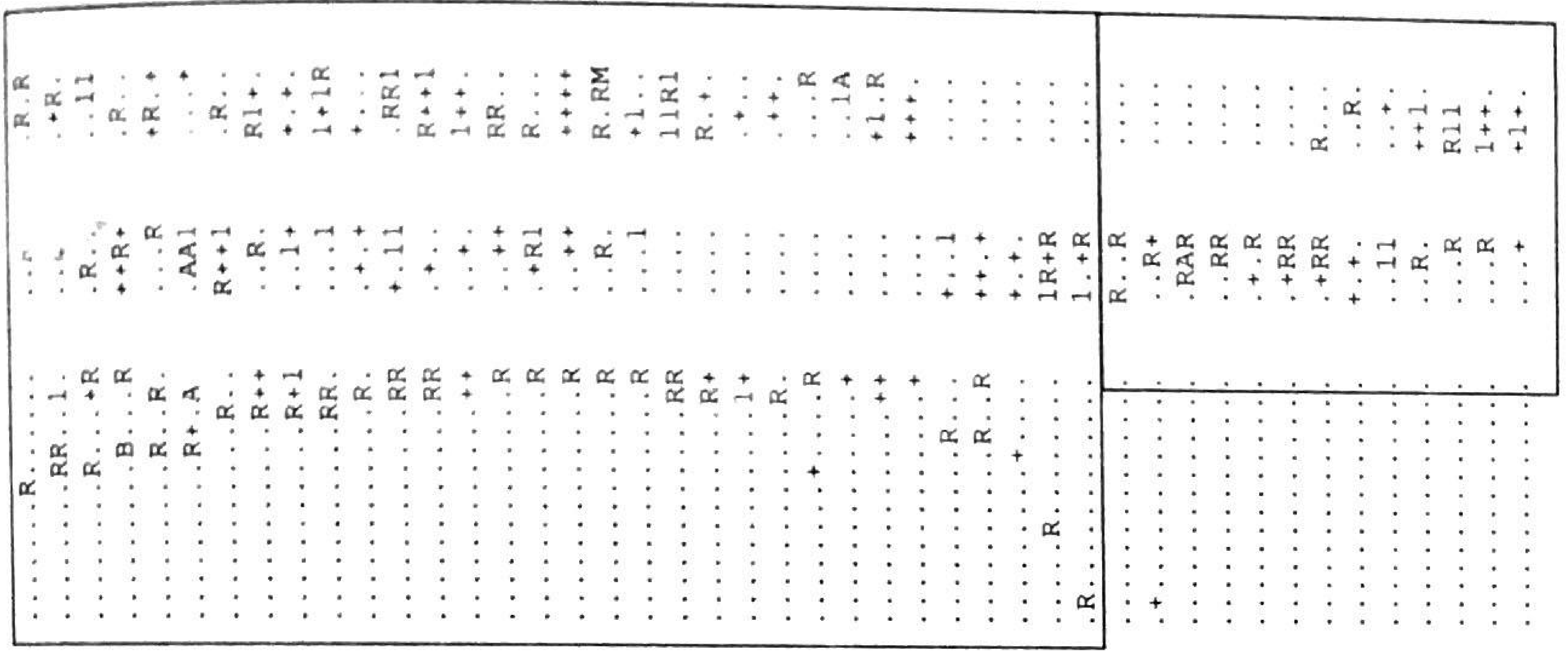

$\therefore$

ar. 
Quimio

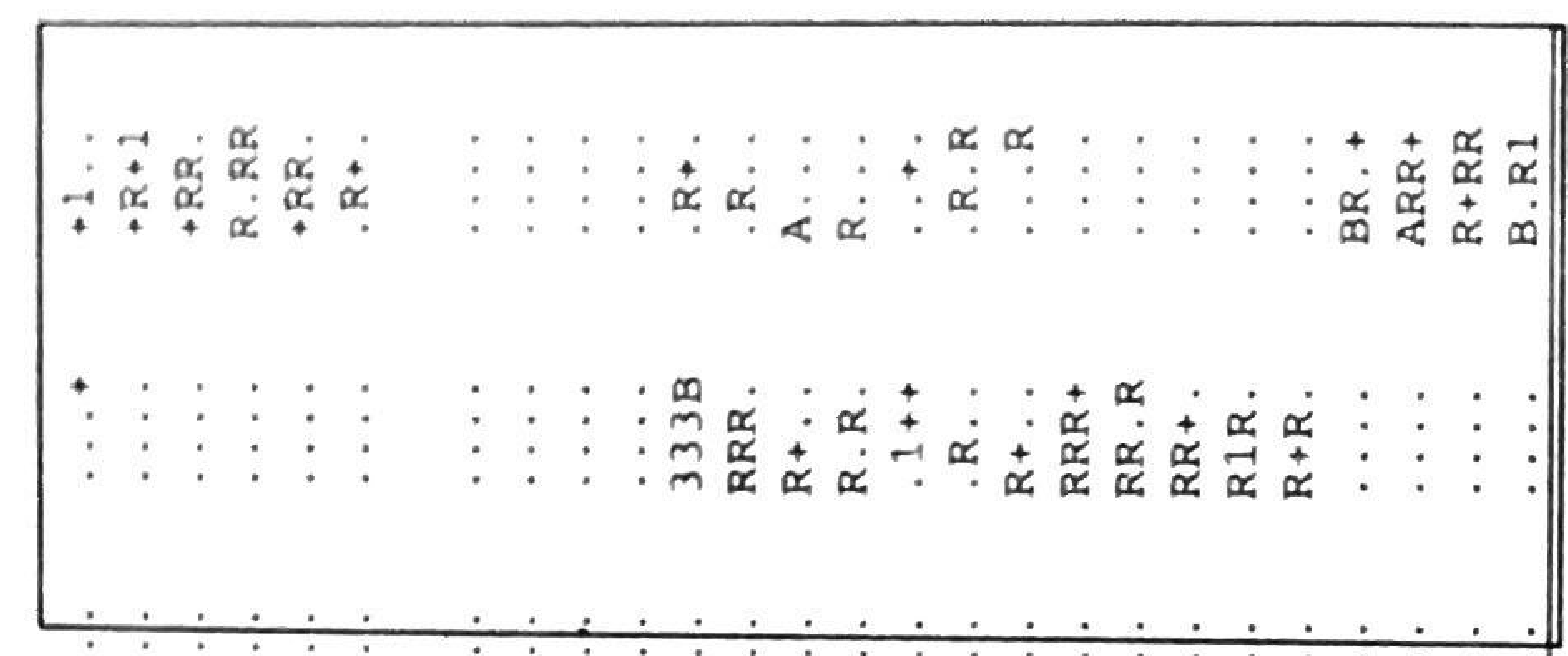

$\infty$

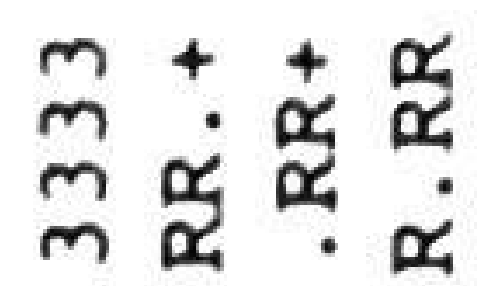

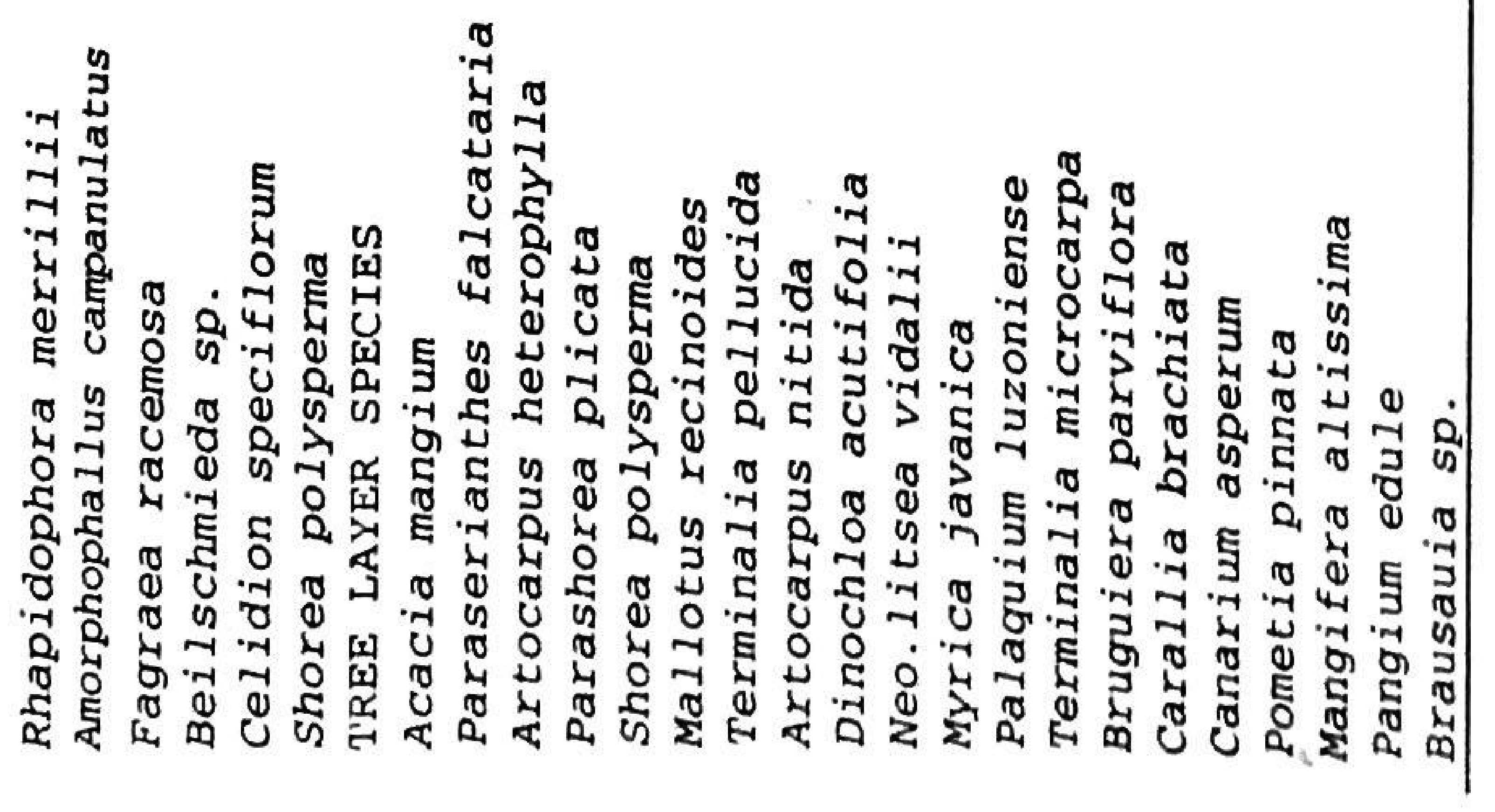

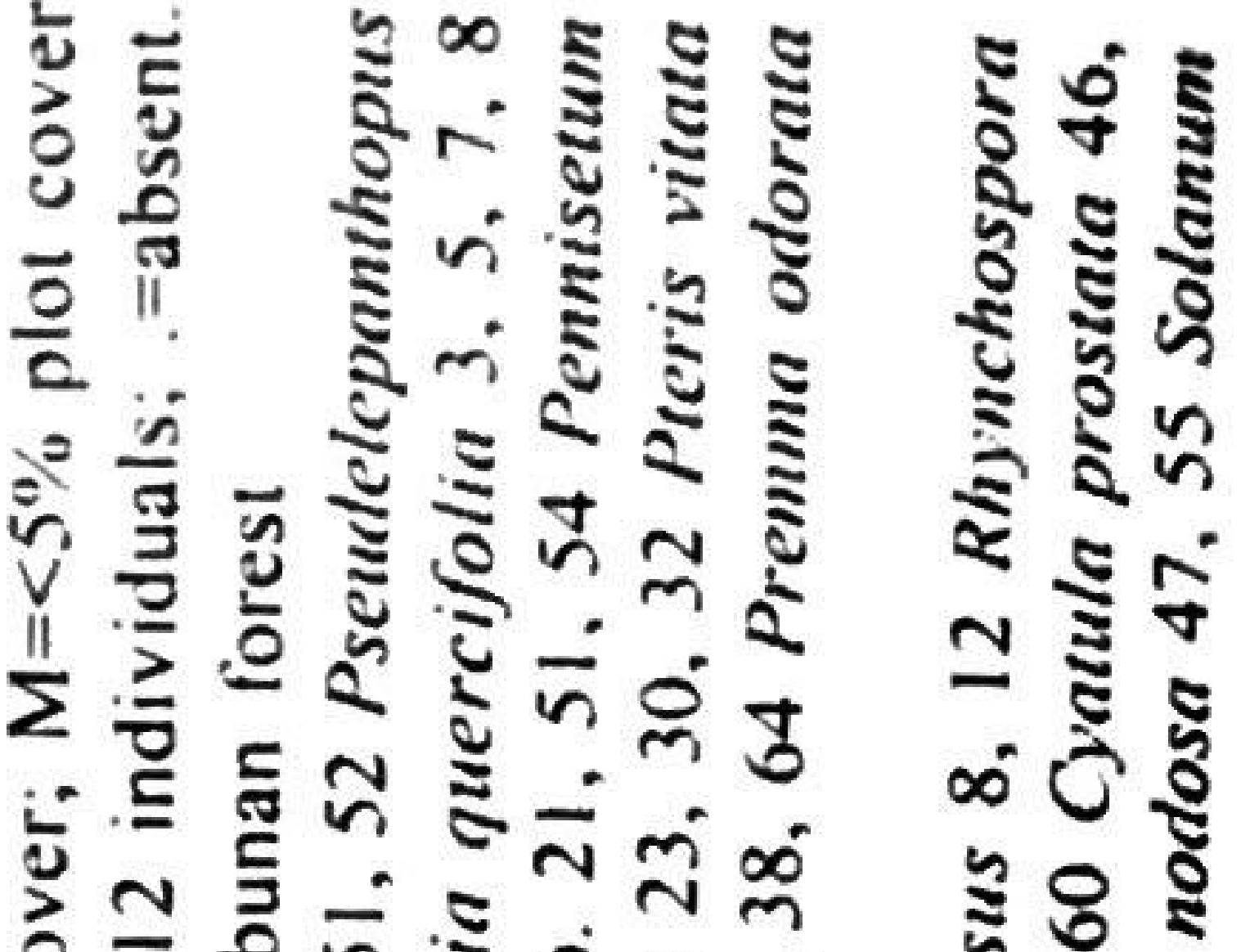

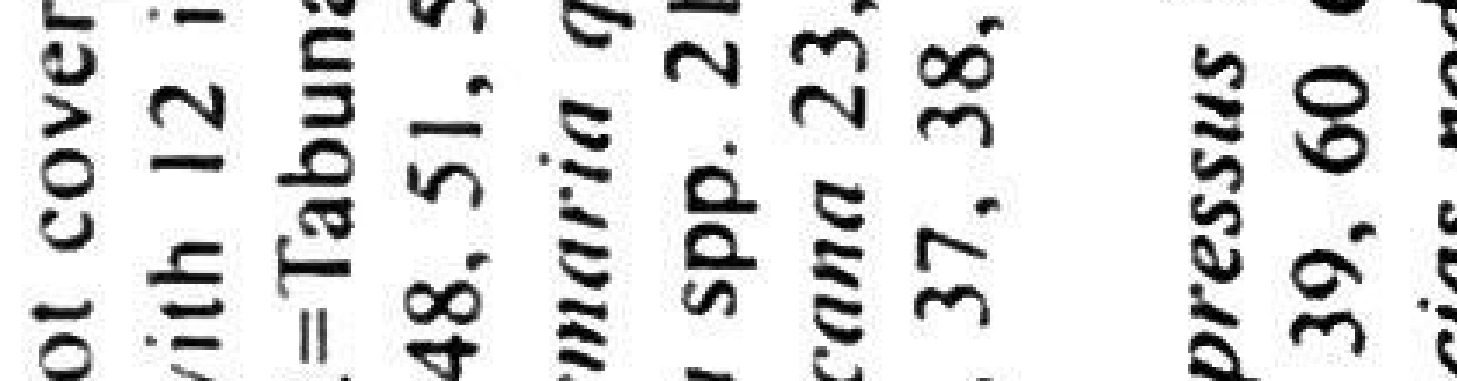

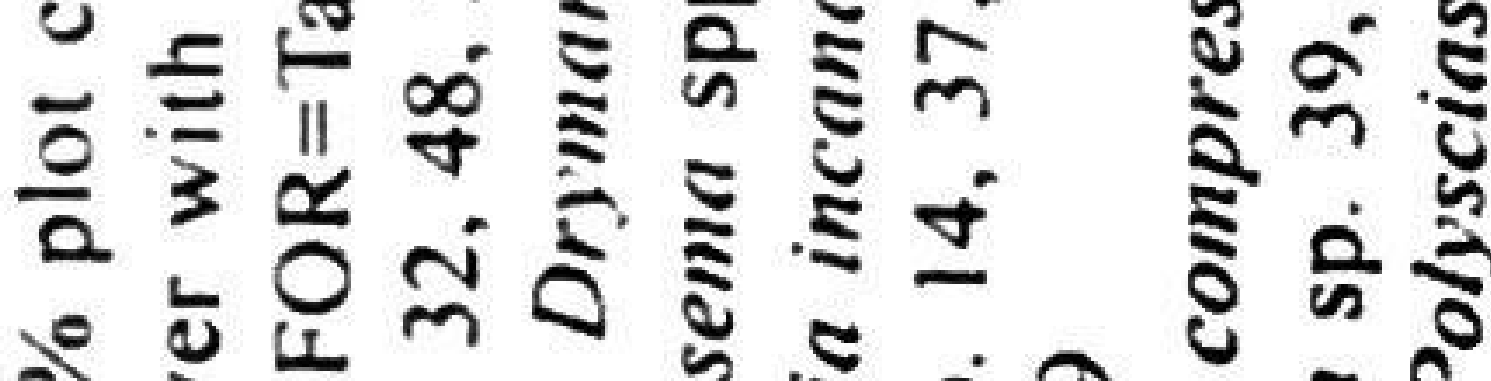

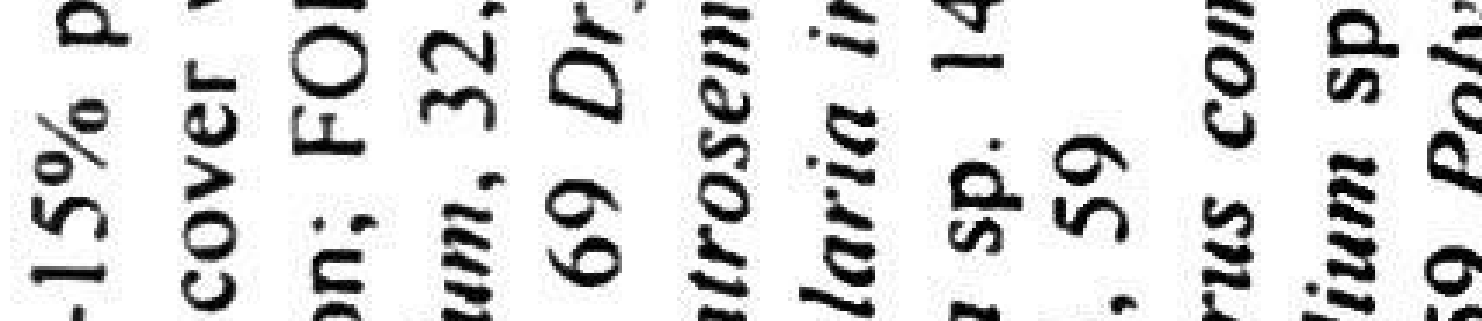

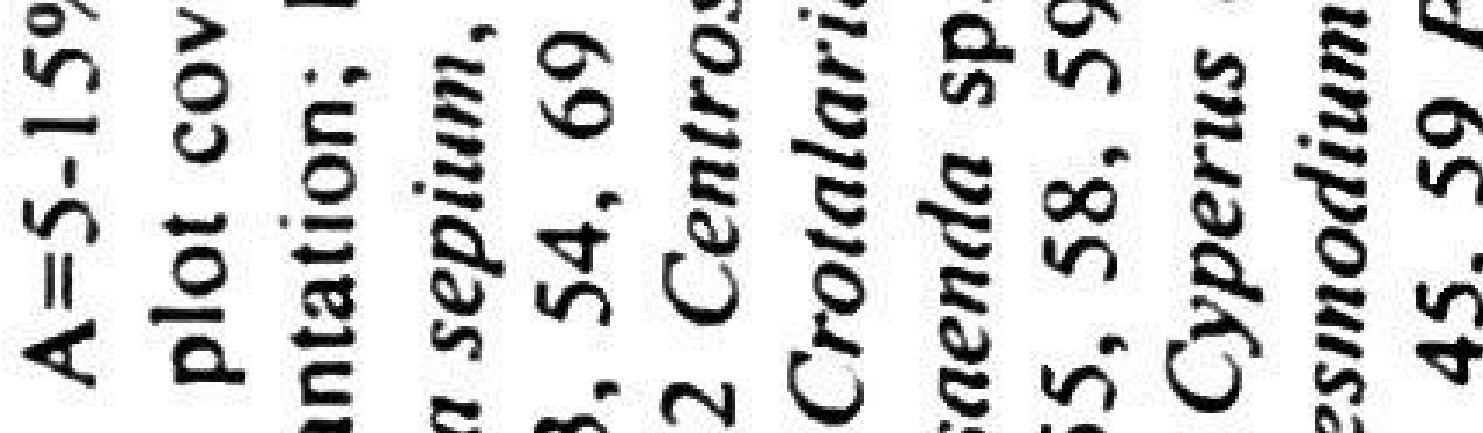

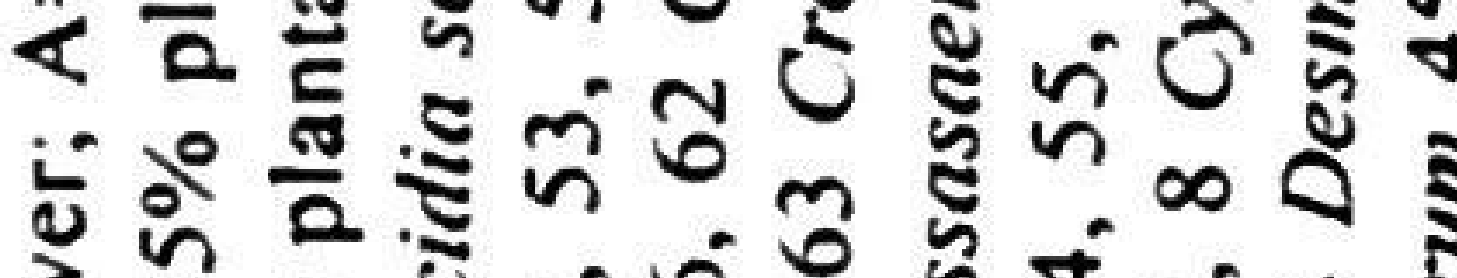

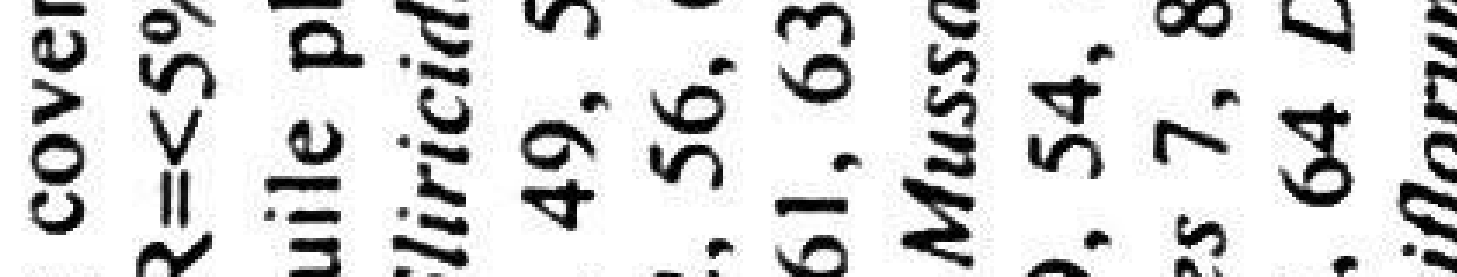

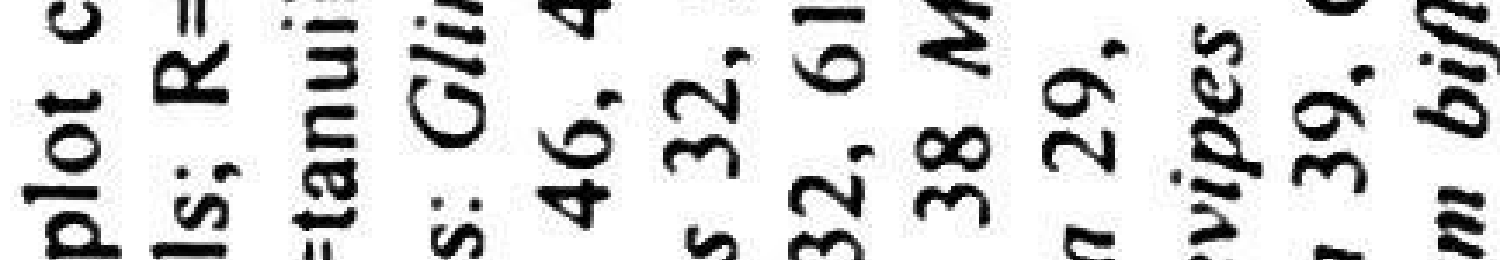

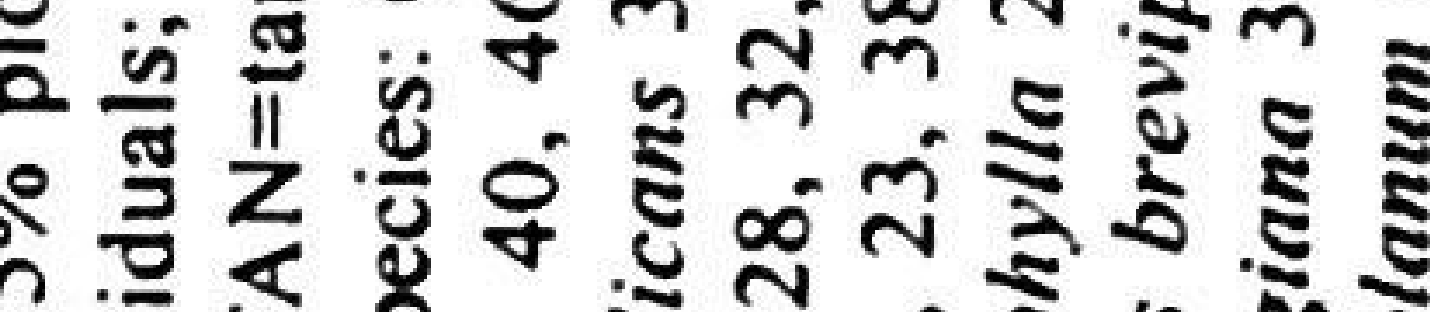

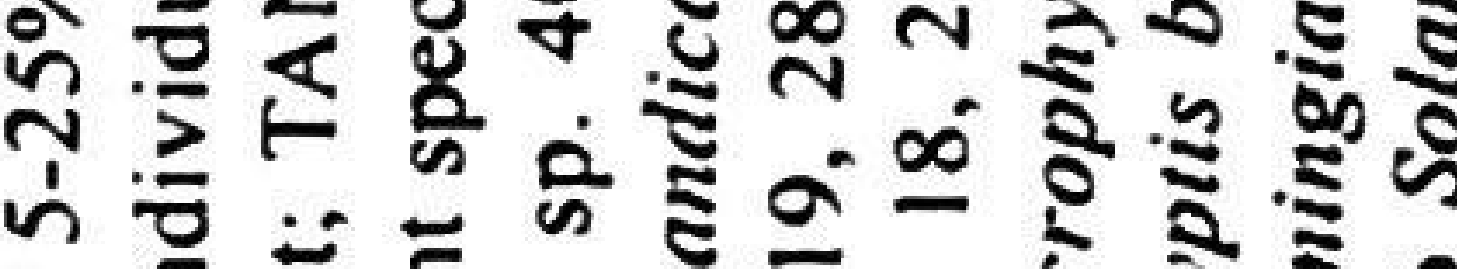

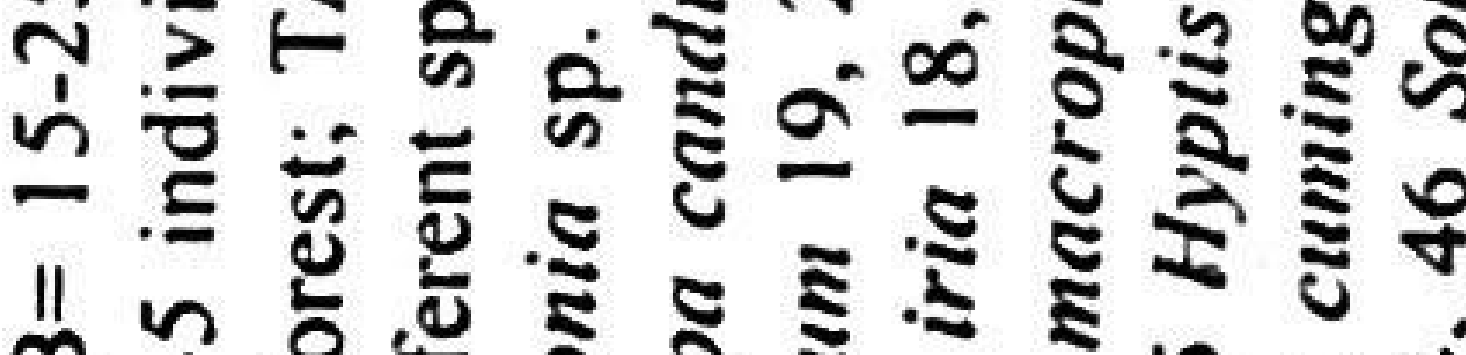

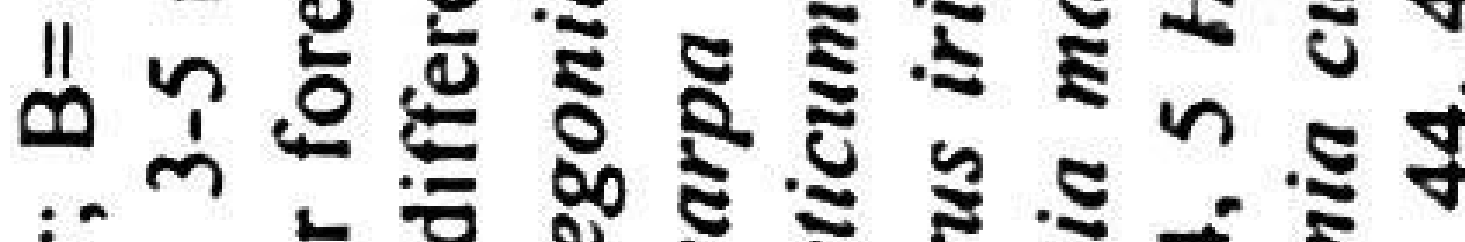

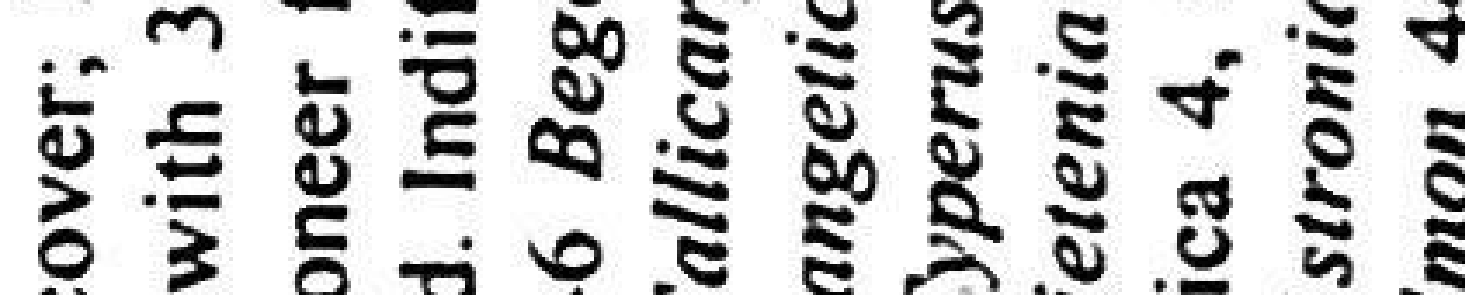

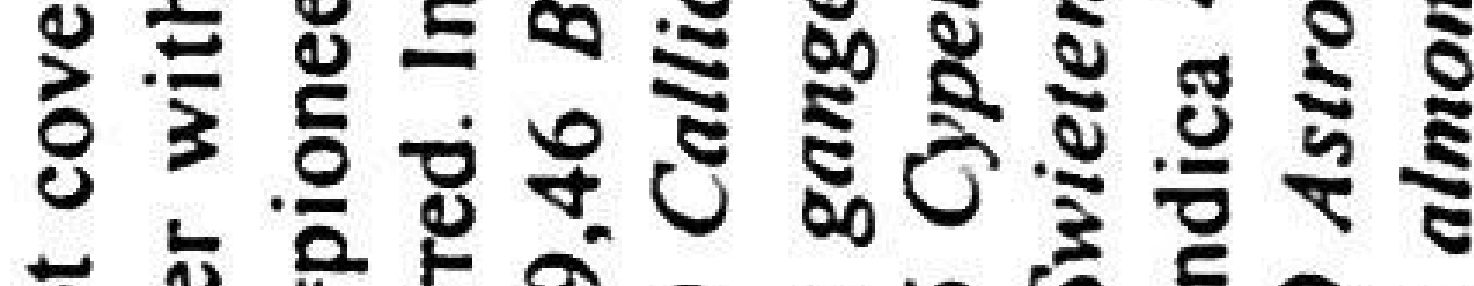

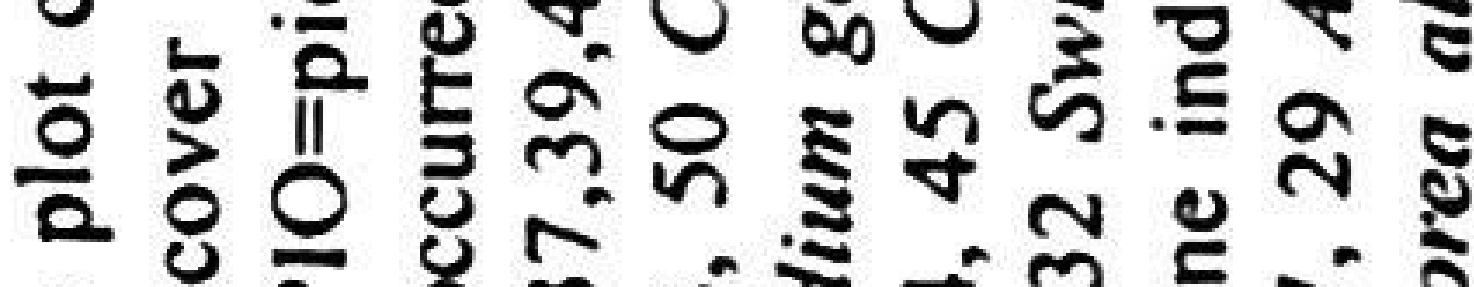

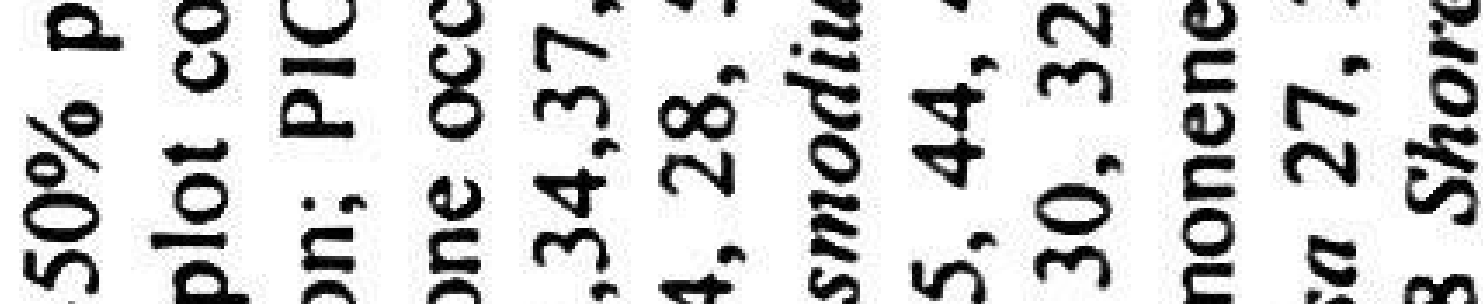

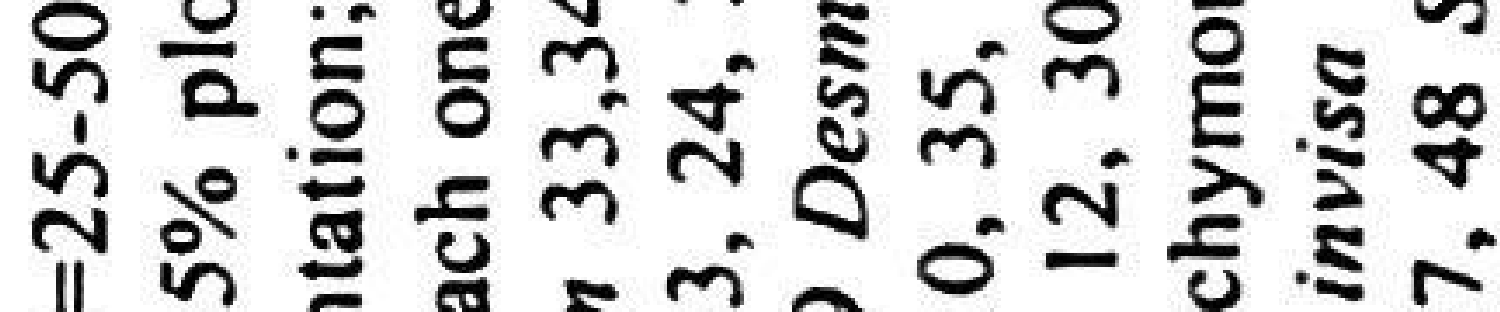
는

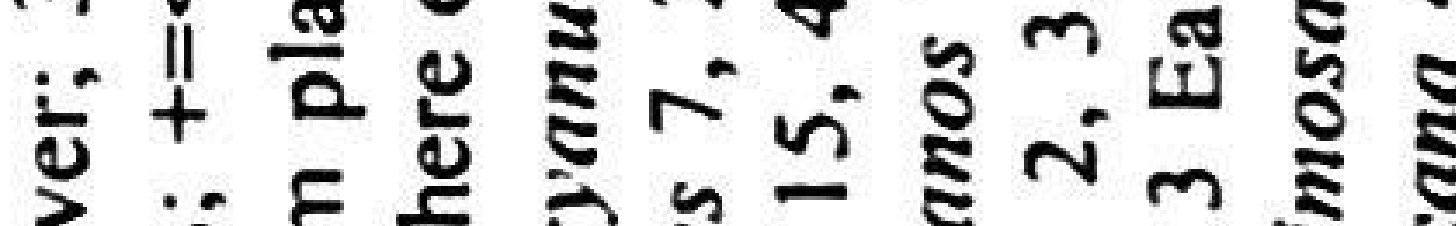

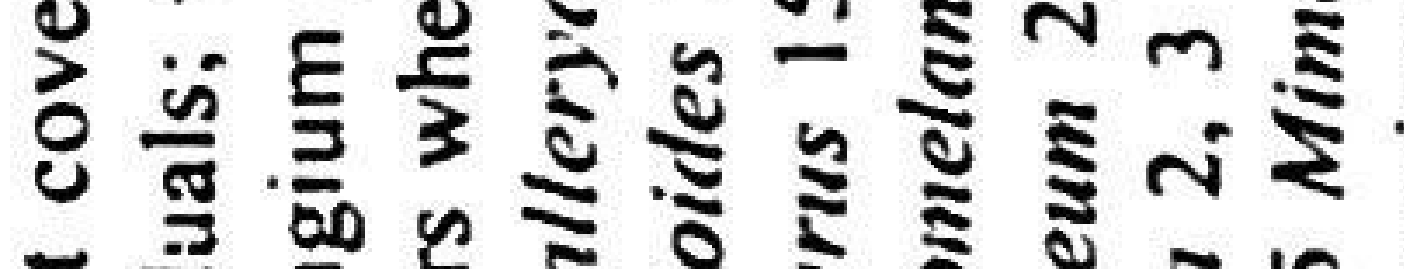

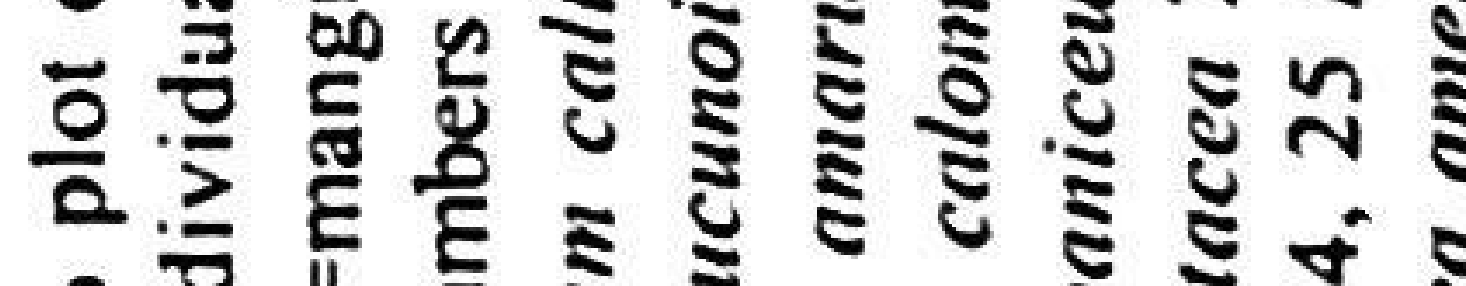

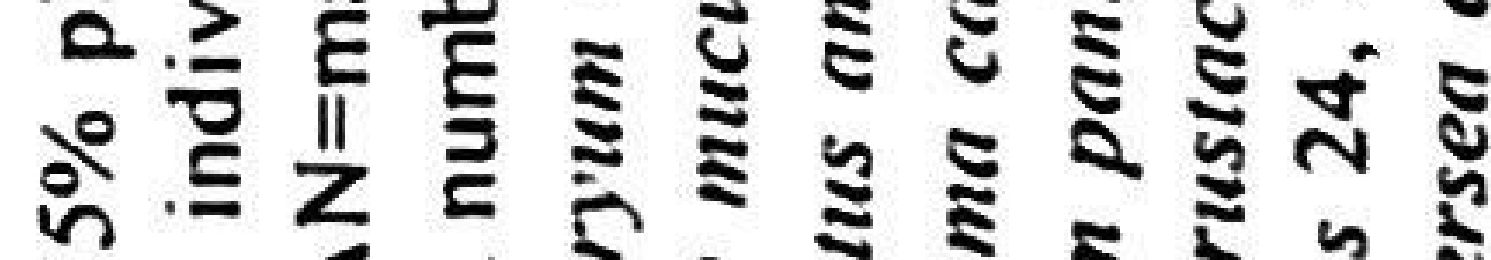

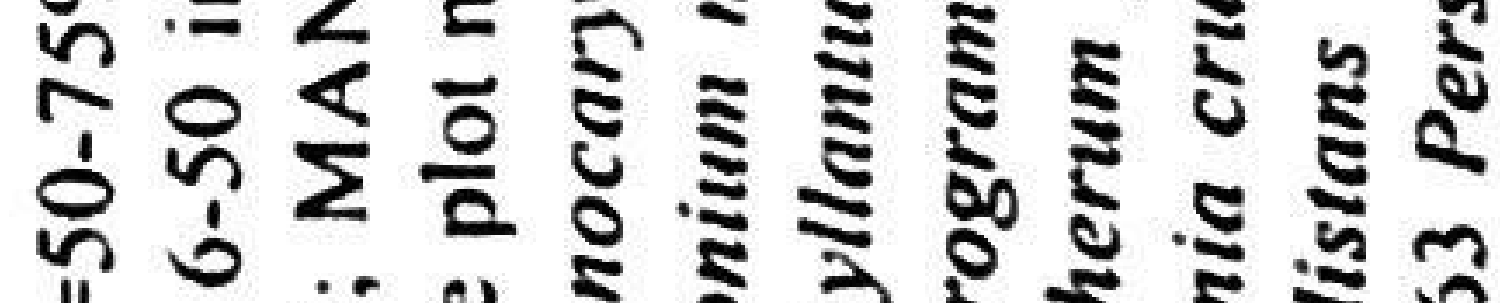
II

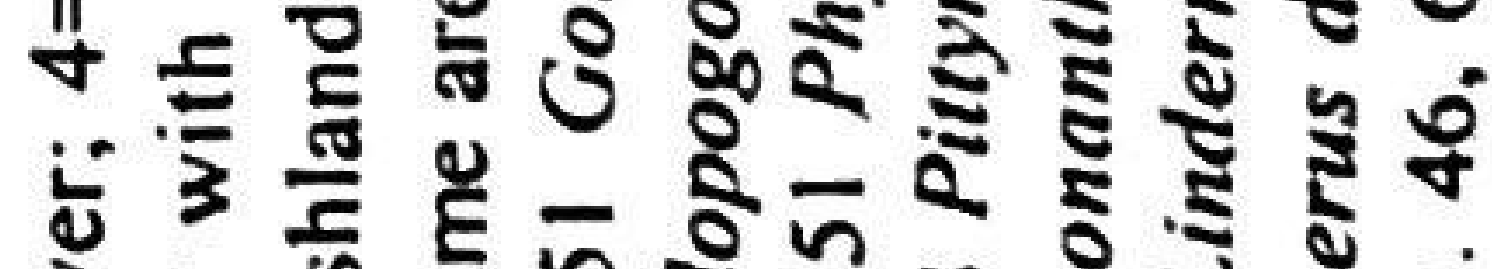

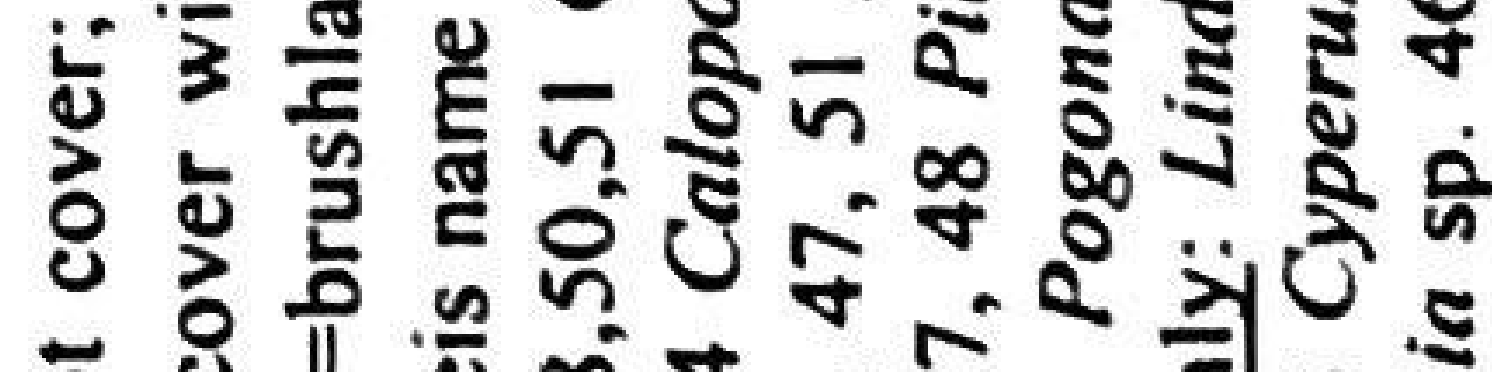

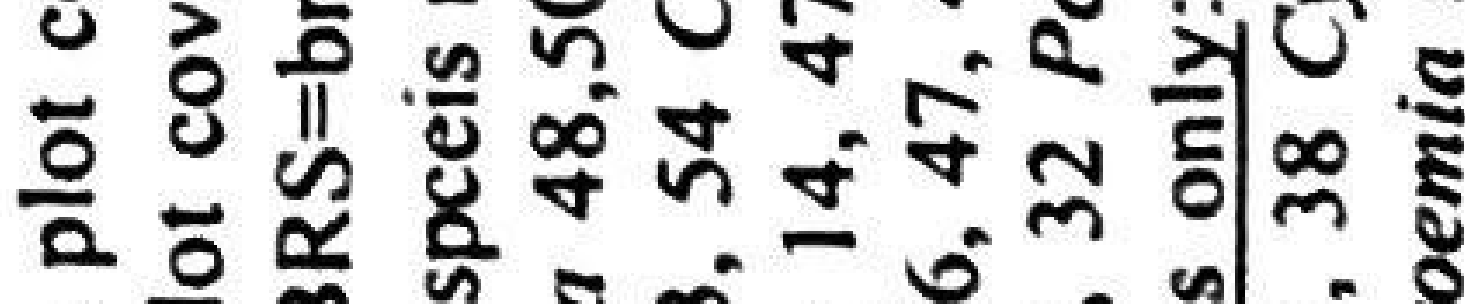

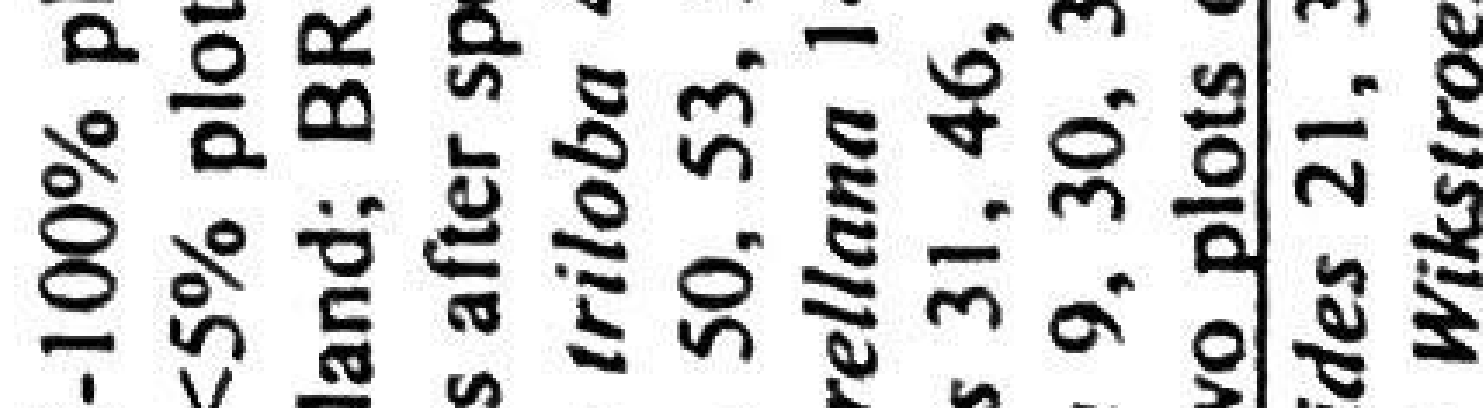

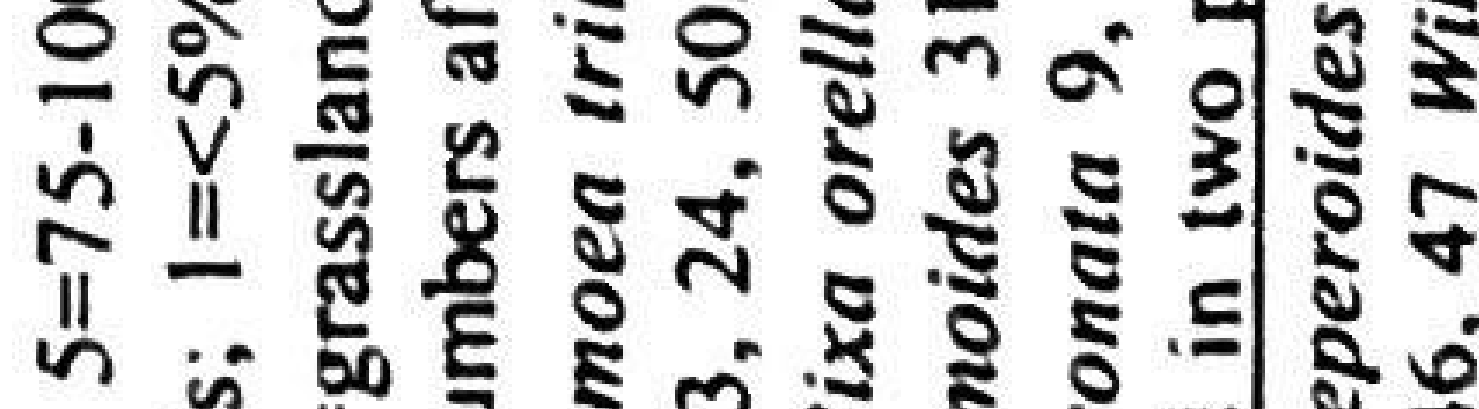

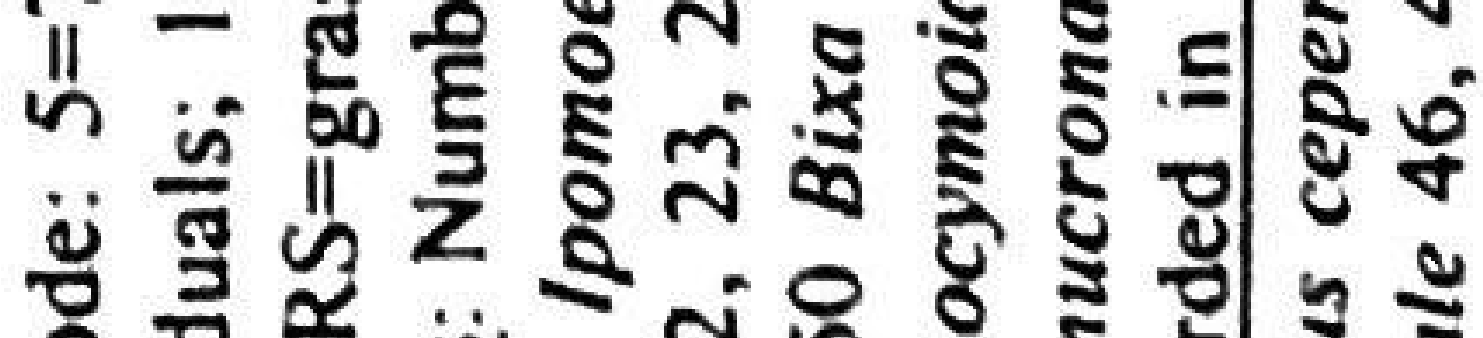

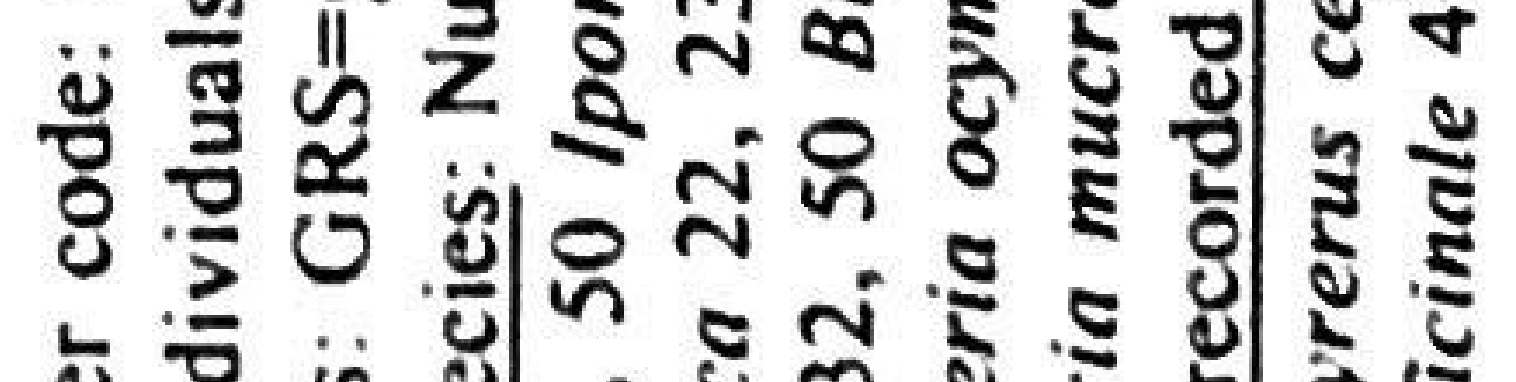

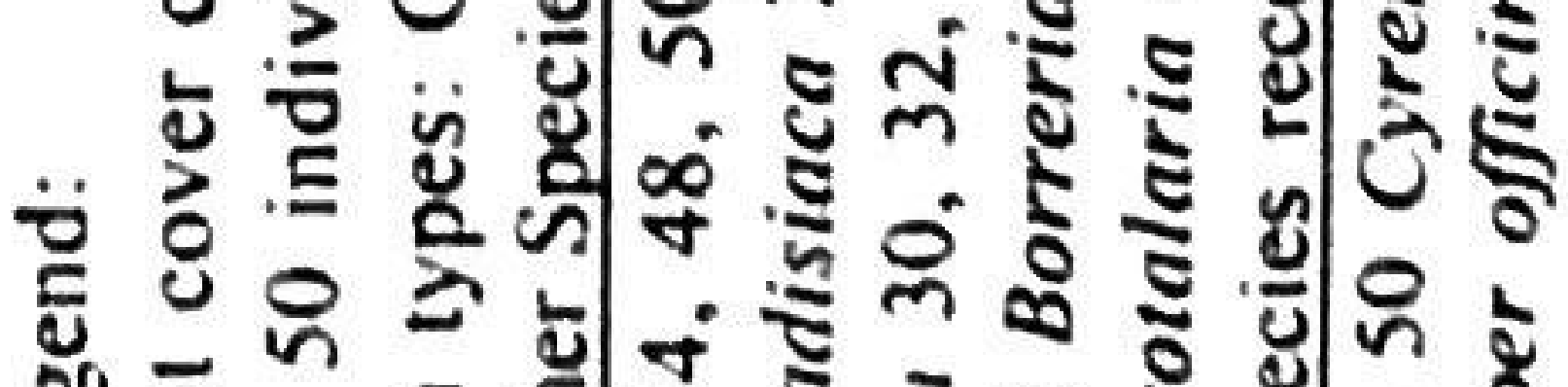

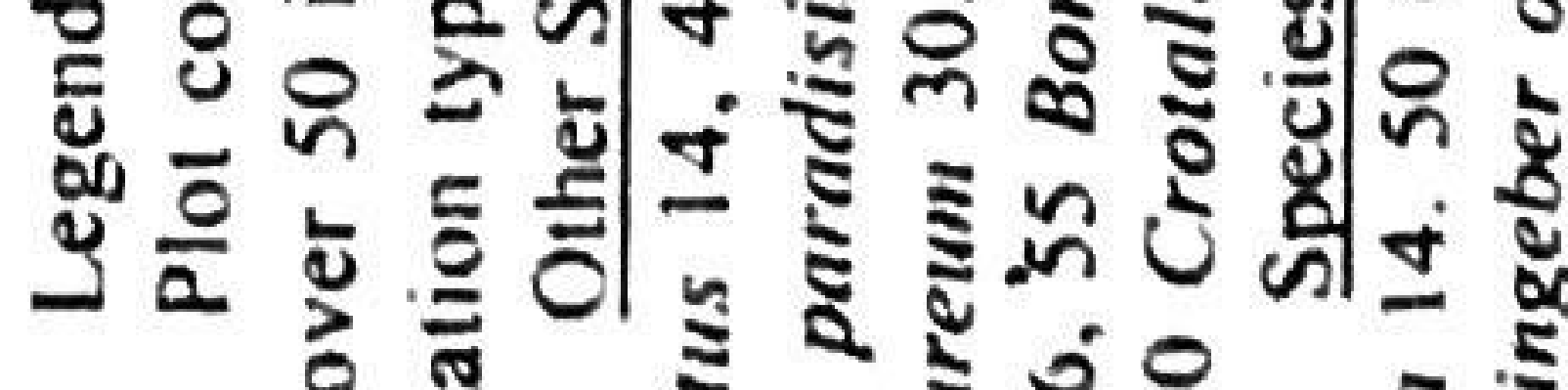

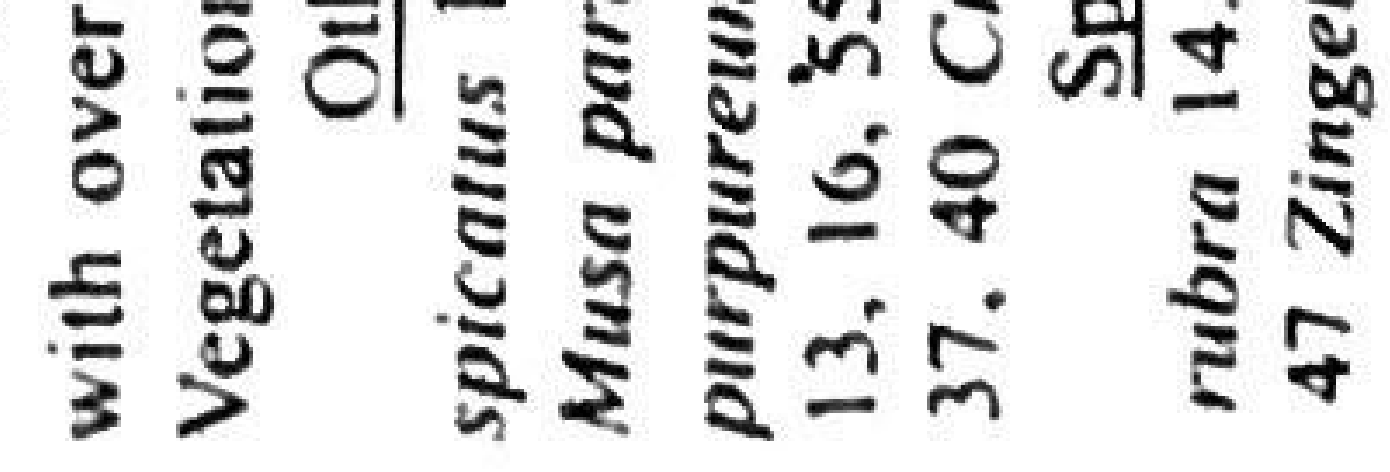


ำ 4

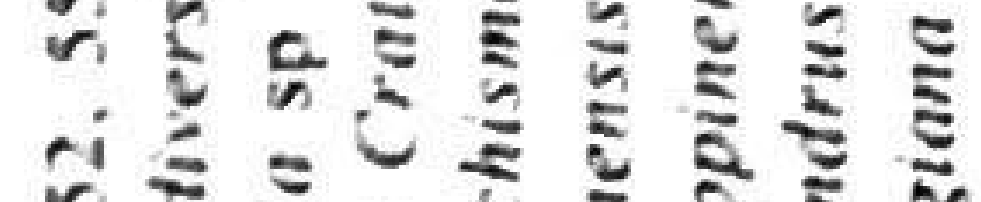

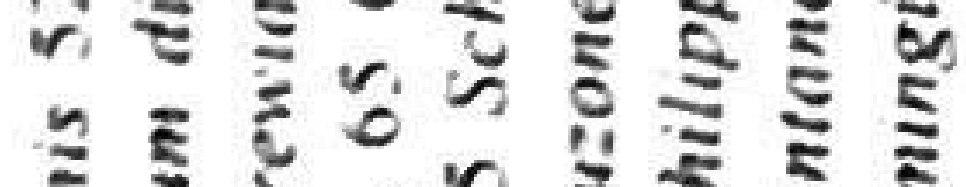
है

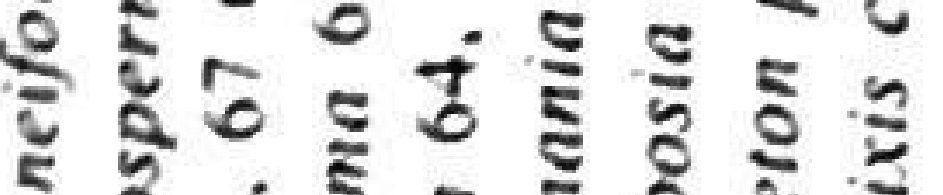

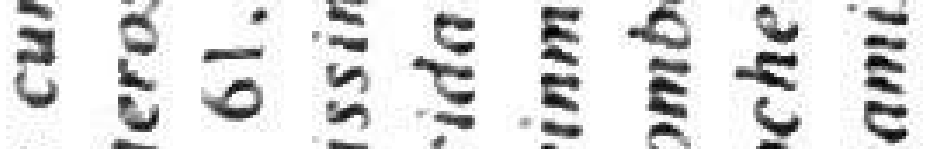

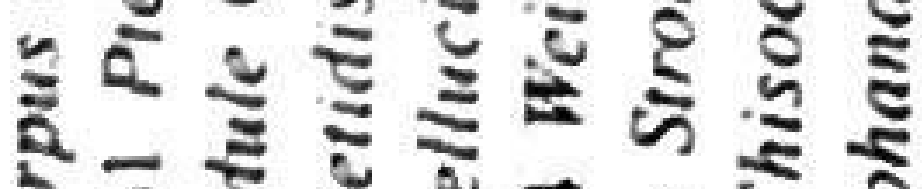

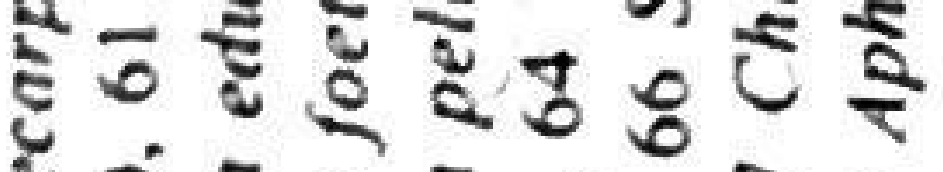

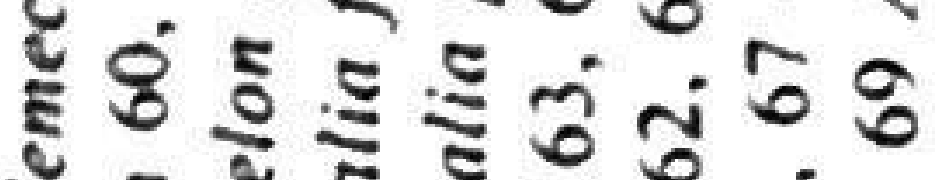

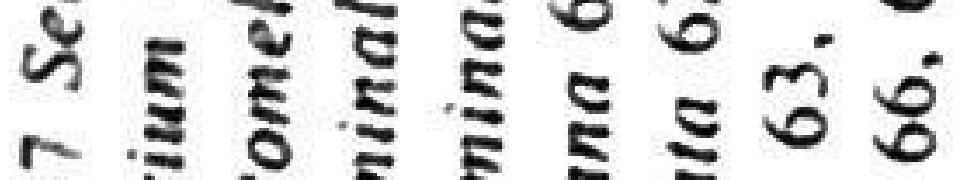
ก่

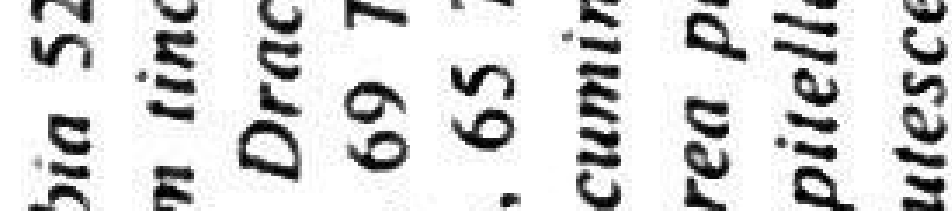
ริ ฐ

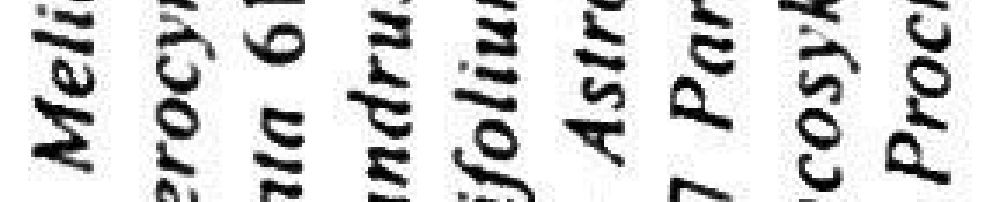

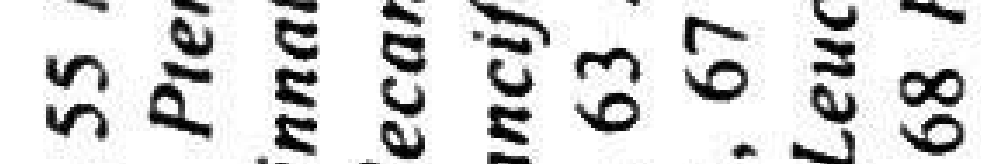
กิธ

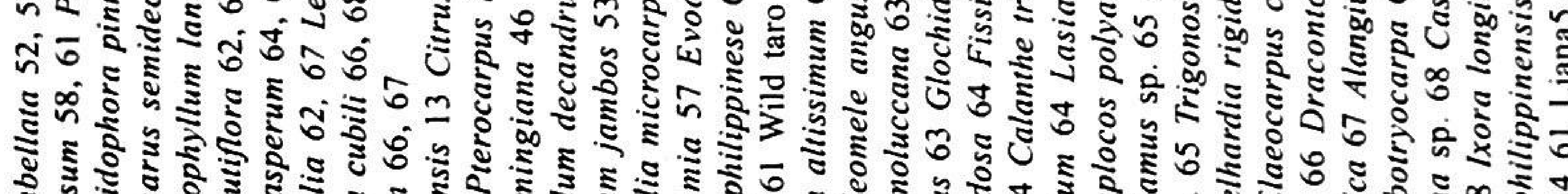

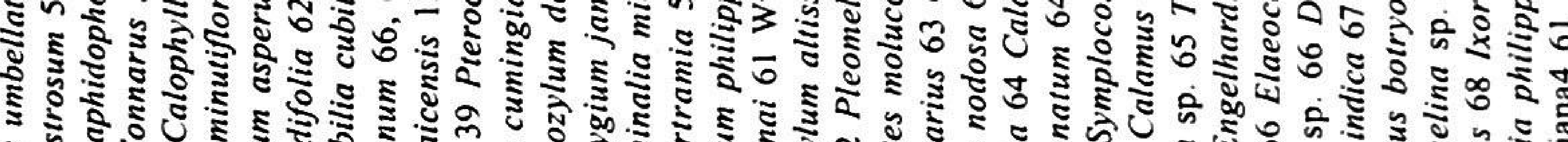
\%

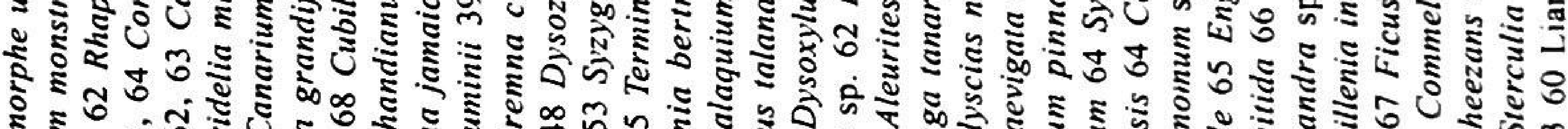

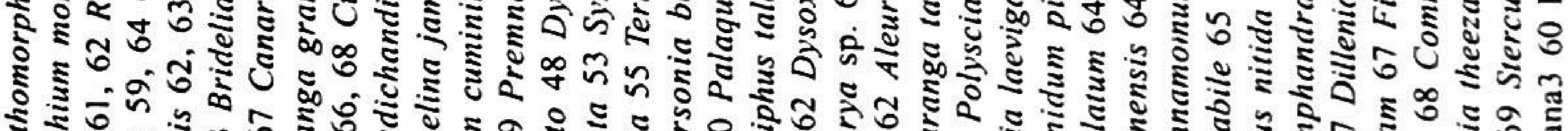

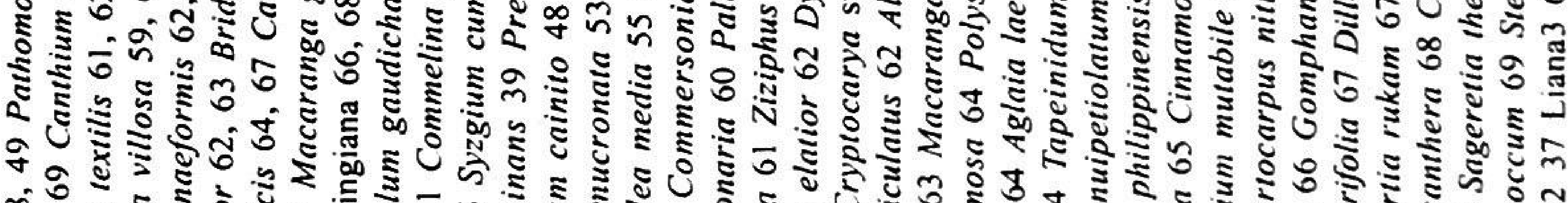

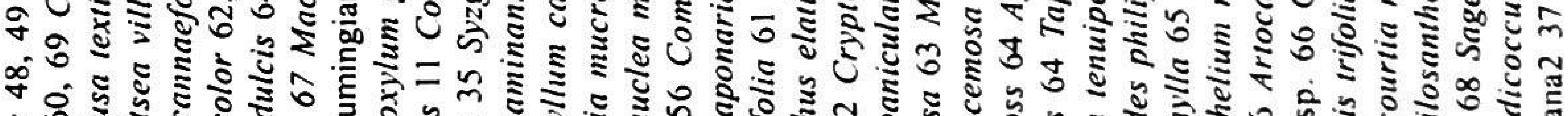

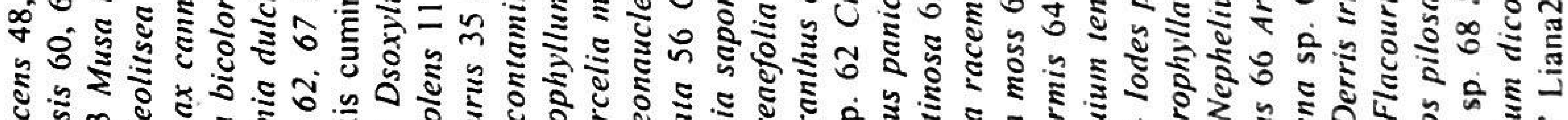

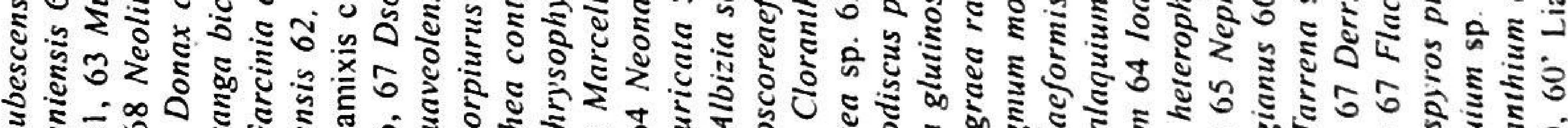
ई

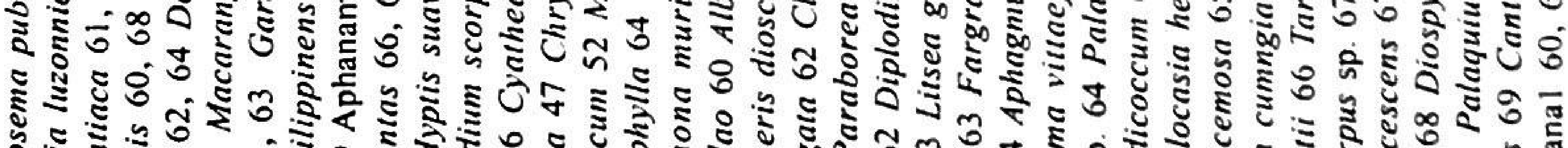

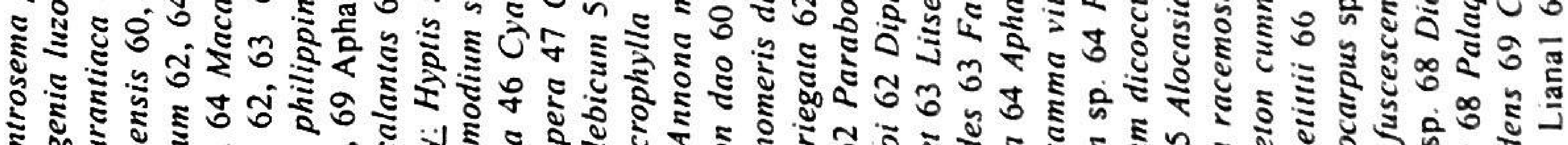

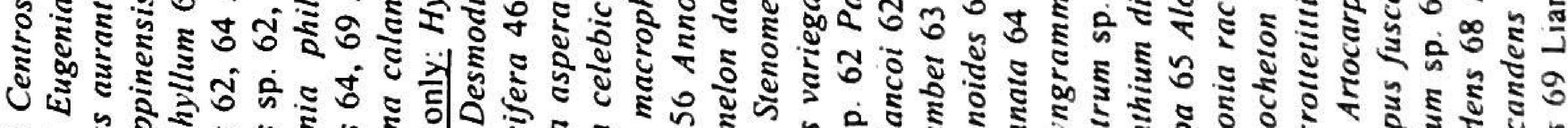

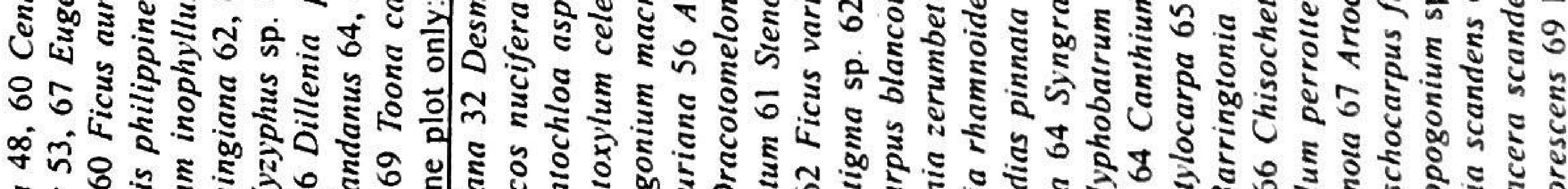

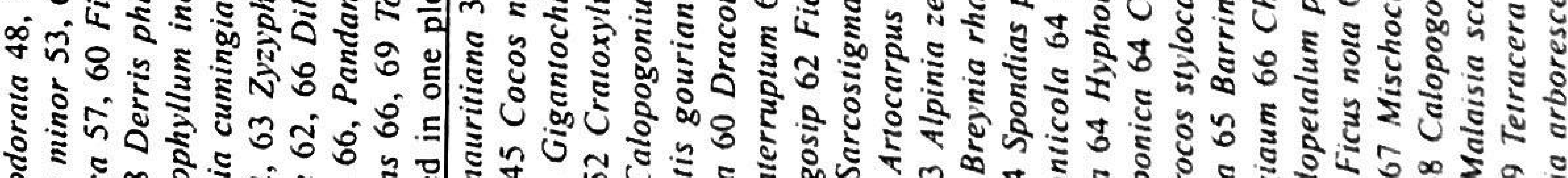

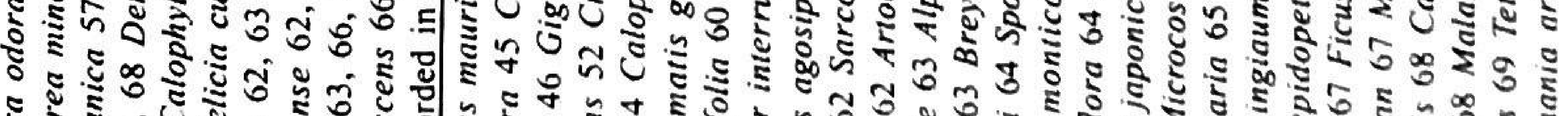

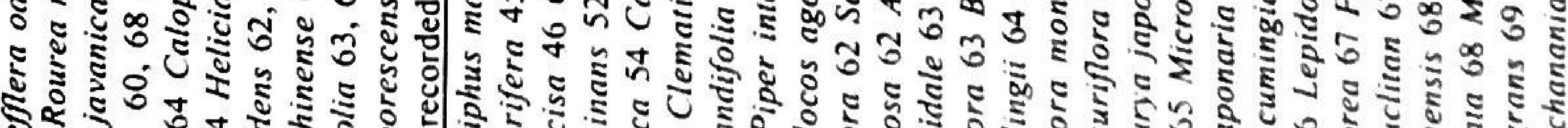

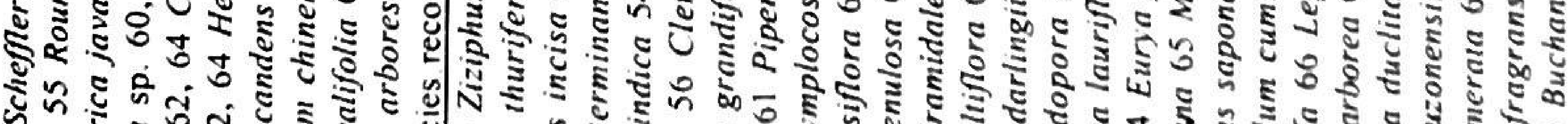

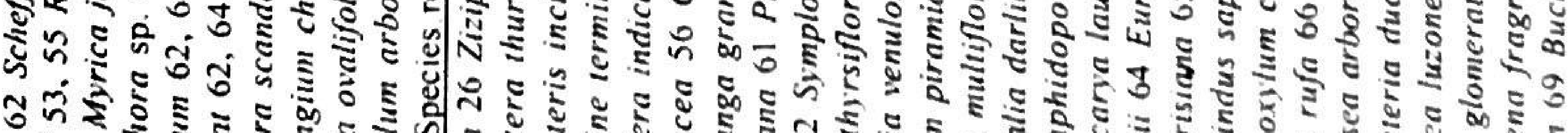

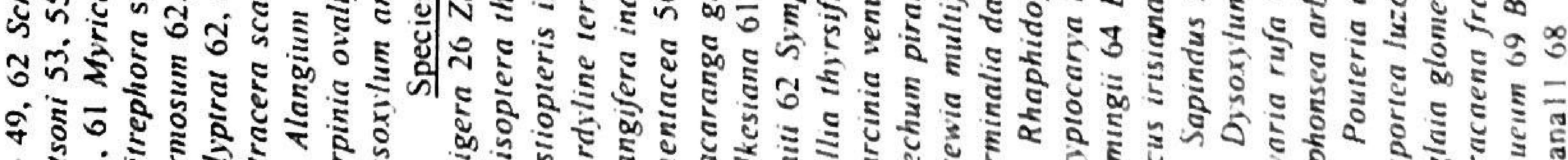

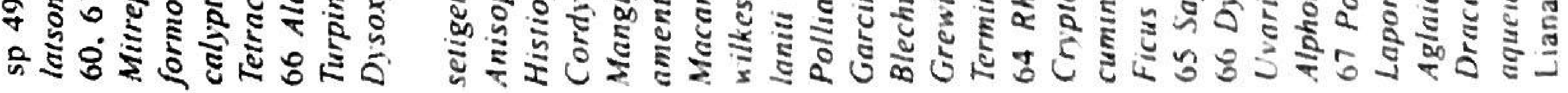

